\title{
Effects of Spray Parameters and Post-spray Heat Treatment on Microstructure and Mechanical Properties of Warm-Sprayed Ti-6Al-4V Coatings
}

\author{
R. M. Molak ${ }^{1} \cdot$ H. Araki ${ }^{1} \cdot$ M. Watanabe ${ }^{1} \cdot$ H. Katanoda ${ }^{2} \cdot$ N. Ohno ${ }^{3} \cdot$ \\ S. Kuroda ${ }^{1}$
}

Submitted: 28 April 2016/in revised form: 1 September 2016/Published online: 9 December 2016

(c) The Author(s) 2016. This article is published with open access at Springerlink.com

\begin{abstract}
Warm spray is a novel thermal spray technique that allows the formation of dense and relatively pure Ti-6Al-4V coatings due to its capability to control the temperature of the propellant gas by diluting the combustion flame with an inert gas such as nitrogen. Recently, its combustion pressure has been increased from 1 to $4 \mathrm{MPa}$ aiming to further increase particle velocity to over $1000 \mathrm{~m} /$ s. Two series of coatings with combustion pressure of 1 and $4 \mathrm{MPa}$ and various nitrogen flow rates were prepared in this study. Effects of combustion pressure and nitrogen flow rate on the microstructure and mechanical properties of the Ti-6Al-4V coatings were systematically studied. Miniature tensile specimens with a total length of about $9 \mathrm{~mm}$ were used for static tensile tests. It was found that the spray parameters affect both the porosity and oxygen content of the coatings significantly and had remarkable effects on their mechanical properties. High level of porosity in the Ti-6Al-4V coatings reduced the effective cross-sectional area of the mini-specimens and caused a drop in their tensile strength and Young's modulus. Subsequent heat treatments were found effective in significantly recovering the mechanical properties of the as-sprayed coatings.
\end{abstract}

Keywords mechanical properties - microstructure - minispecimen $\cdot$ oxygen content $\cdot$ porosity $\cdot$ tensile test $\cdot$ warm spraying

\footnotetext{
R. M. Molak

Rafal.Molak@wimpw.edu.pl

1 National Institute for Materials Science (NIMS), Tsukuba, Japan

2 Kagoshima University, Korimoto, Kagoshima, Japan

3 Plasma Giken Co. Ltd., Toda, Saitama, Japan
}

\section{Introduction}

There are two main application areas of titanium alloys in the aerospace industry, i.e., airframes and aero engines, driven by their superior properties such as high strength, fatigue resistance and creep resistance at low-to-moderate temperatures in combination with low density and low modulus (high flexibility). Because of difficulties in casting and welding of titanium alloys due to the high affinity to oxygen and the high solid solubility of oxygen (about $14.5 \%$ ) (Ref 1), however, there is a demand for direct fabrication of metal parts in near-net shapes (NNS), which can produce complex components with minimal waste of material (Ref 2). In aerospace industry, for example, the buy-to-fly ratio, which is the ratio of the mass of material needed to machine a part to the mass of material in the finished component, may be in the range of 1.5:1 for turbine blades to over 22:1 for complex shapes structural components. For compressor and ring sections, the ratio is approximately 12:1 and an analysis performed by Pratt and Whitney indicated that the ratio could be reduced by $41 \%$ to $7: 1$ by using cold spray for parts manufacturing (Ref 3 ).

Another practical application of thermal spray is to repair local damage on finished parts (Ref 4, 5). It allows reclamation components, which otherwise have to be removed prematurely because of corrosion, erosion, abrasive wear or fatigue. Currently, many of these worn titanium parts cannot be reclaimed due to the lack of means to restore them for service. For instance, various welding processes have been developed, but tend to induce undesirable thermal stresses that can lead to premature failure.

Hence, there is a great expectation for thermal spray technology as a potential method for both production and repair of Ti-based materials. Because of the high oxygen affinity of titanium and the possibility to form the hard and 
brittle $\alpha$-case, it is necessary to avoid oxidation of titaniumbased deposits as much as possible. One of the techniques that has explored is low-pressure plasma spray (LPPS). It suppresses the oxidation of the feedstock powder through operation in an inert atmosphere under low-pressure conditions. The LPPS equipment costs are rather high. Another potential and newer technique is cold spraying (CS), in which metallic powder is accelerated by a supersonic gas jet generated by expansion of high-pressure gas through a convergent divergent nozzle. By using inert gas as a propellant, it is possible to essentially eliminate oxidation of the feedstock powder during processing. Even though the most recent CS equipment operates with a gas pressure of $4 \mathrm{MPa}$ and a temperature close to $1000{ }^{\circ} \mathrm{C}$, it is still difficult to form dense coatings of especially high-strength materials such as Ti-6Al-4V, because of the high critical velocity required to form bonding between deposited particles. To achieve a sufficient particle velocity, helium as a propellant gas has to be used (Ref 6,7). The shortage and high cost of helium however, a gas recycling facility is required for industrial scale production, which would be a large initial investment.

Recently, a novel spray process called warm spraying (WS) (Ref 8-10), which is a modification of high-velocity oxy-fuel (HVOF) spraying, has been used to produce Ti$6 \mathrm{Al}-4 \mathrm{~V}$ coatings. In this process, the temperature of a supersonic gas flow generated by combustion of kerosene and oxygen is controlled by diluting the combustion flame with an inert gas such as nitrogen. The inert gas is injected into the mixing chamber placed between the combustion chamber and the powder feed ports, and thus, the temperature of the propellant gas can be controlled over a wide range. These advantages allowed to produce Ti-6Al-4V coatings with low porosity and low oxygen content of $1.1 \mathrm{vol} . \%$ and 0.27 mass\%, respectively, under an optimized spray condition (Ref 11).

The above-mentioned Ti-6Al-4V coatings by WS, if considered for manufacturing and repairing of components, need appropriate mechanical properties to meet the specific requirements determined by the standards and specifications of each part. It is well known that typical microstructure of thermally sprayed coatings is characterized by the existence of pores, microcracks, splat boundaries, oxides and unmelted particles, which have great impact on the mechanical properties. For example, increased porosity leads to a decrease in elastic modulus and tensile strength of the coatings compared to the bulk material, but the pore morphology is also very important. At the same time, these imperfections in the microstructure tend to degrade plastic properties, which is due to the fact that voids act as a kind of notches and cause localized strain concentrations during tensile loading.
There have been several reports about the tensile properties of Ti-6Al-4V deposits obtained by CS (Ref 3, 12, 13) and LPPS (Ref 14). In general, the ultimate tensile strength and elongation to failure were lower compared to the bulk material primarily due to the existence of discontinuity in the microstructure of the coatings, which resulted in weak bonding between deposited Ti-6Al-4V particles. Blose et al. (Ref 3), Wong et al. (Ref 12) and Vo et al. (Ref 13) reported significant decrease in tensile strength for Ti-6Al$4 \mathrm{~V}$ coatings formed by $\mathrm{CS}$ when compared to bulk material, although porosity was lower than $1 \%$ for some specific cold spray conditions. In addition, stress-strain curves generally exhibited brittle failure without plastic deformation. The best in terms of reported mechanical properties were obtained for coatings formed by LPPS (Ref 14), which was due to the low porosity, low level of oxide content and relatively high process temperature, which could improve interfacial bonding between the deposited particles. However, it should be noted that elongation to failure was as low as $1 \%$. It was reported, however, that heat treatment at elevated temperatures increased both tensile strength and ductility due to the increase in metallurgically bonded area between particles. Wong et al. (Ref 12) reported that cold-sprayed coatings using helium exhibited tensile strength about $85 \%$ of the minimum required bulk value; however, only minor increase in elongation to failure was observed. Significant enhancement in both ductility and tensile strength was obtained for Ti-6Al-4V coatings subjected to hot isostatic pressing (HIP) process, which resulted in further reduction in porosity (Ref 3). In this case, determined values of tensile strength and elongation to failure reached $900 \mathrm{MPa}$ and $13 \%$, respectively.

Although it is possible to partially recover the mechanical properties by heat treatments of Ti-6Al-4V deposits, the remaining microstructure (porosity and oxygen content, phase composition and degree of deformation) still has major influence.

Recently, through collaboration among the National Institute for Materials Science (NIMS), Kagoshima University and Plasma Giken Co. Ltd., the combustion pressure of WS was increased from approximately 1 (lowpressure warm spray) to $4 \mathrm{MPa}$ (high-pressure warm spray) with some internal design modifications of the fuel injector and expansion nozzle (Ref 15), which resulted in increase in sprayed particle's velocity; for a titanium particle of around $30 \mu \mathrm{m}$ diameter, velocity close to $1100 \mathrm{~m} / \mathrm{s}$ was measured. Molak et al. (Ref 11) reported recently that due to the velocity enhancement Ti-6Al-4V coatings with better quality in terms of both porosity and oxygen content in contrast to the low-pressure WS were obtained. In order to compare the mechanical properties of coatings by the highpressure WS with the reference values obtained by CS and 
LPPS coatings, tensile testing of mini-specimens has been employed in this study. Effects of warm spraying parameters and heat treatment on the deposits' mechanical properties (i.e., Young's modulus, yield strength, ultimate tensile strength and elongation to failure) of Ti-6Al-4V deposits were examined and discussed with their microstructural features.

\section{Experimental Procedures}

\section{Materials}

Commercially available Ti-6Al-4V ELI ${ }^{1}$ powder (Raymor Industries, Ltd., Québec, Canada) manufactured by gas atomization with near-spherical morphology was used. The powder had a Gaussian size distribution from 1 to $75 \mu \mathrm{m}$ with an average particle size of about $30 \mu \mathrm{m}$. Its morphology, size distribution and composition can be found in a previous paper (Ref 11). Substrates were $100 \times 50 \times 5 \mathrm{~mm}$ plates made of low carbon steel JIS: SS400, which were grit-blasted with alumina powder and cleaned using acetone before spraying.

\section{Warm Spray Conditions}

During the development of high-pressure warm spray (HPWS), numerical simulation carried out by Katanoda et al. (Ref 15) and experiments performed by Molak et al. (Ref 11) showed that several internal design modifications of the spray apparatus resulted in an increase in the combustion pressure from 1 to $4 \mathrm{MPa}$ and accelerates $30-\mu \mathrm{m}$ titanium particles to more than $1100 \mathrm{~m} / \mathrm{s}$ under some specific conditions. This is a significantly higher than the velocity range reached by the previous low-pressure WS $(\sim 750 \mathrm{~m}$ / s).

Two series of samples were prepared by high- and lowpressure warm spray with three nitrogen flow rates of $0.5,1$ and $1.5 \mathrm{~m}^{3} / \mathrm{min}$ (Table 1 ). The spray distance and the barrel length were fixed at $200 \mathrm{~mm}$ as these were found to be optimal for the warm spraying of Ti-6-Al-4V coatings in a previous study (Ref 11$)$.

In order to cut mini tensile test specimens out of the sprayed coatings, all deposits were approximately 2-4 mm in thickness.

\footnotetext{
1 Ti6-Al-4V ELI (grade 23) is very similar to Ti-6Al-4V (grade 5), except that Ti-6Al-4V ELI contains less nitrogen, carbon, iron and especially oxygen. ELI stands for "Extra Low Interstitial" and this feature provides improved ductility and good fracture toughness.
}

\section{Mechanical Properties}

Due to the limited volume of the testing material, tensile tests on mini-specimens were carried out to investigate the mechanical properties of the Ti-6Al-4V coatings by WS. The shape of the mini-specimens was machined using a wire electro-discharge machine (WEDM) (HS-3600, Brother International Co., Ltd, Bridgewater, United States) with the dimensions given in Fig. 1(a), out of which specimens were sliced to about $0.8 \mathrm{~mm}$ thickness by a diamond wire cutting machine. Usually, three mini-specimens were obtained from an as-sprayed coating of 3-4 mm thickness (Fig. 1b). Finally, mini tensile specimens were manually grinded using \#1000 emery paper in order to reduce surface roughness.

Because of the small size of the specimens, strain gauges were used to measure the elongation during tensile testing. In order to minimalize the error coming from bending effect due to any misalignment between the two grips used to pull a specimen, two strain gauges were attached on the front and back surfaces of a mini-specimen and the mean value of the two strain values was calculated. Since the strain gauge had a limited range of measurable elongation up to $1 \%$, strain was calculated on the basis of the crosshead displacement beyond $1 \%$. This method was successfully used previously in order to determine mechanical properties of titanium deposits (Ref 16) and bulk materials (Ref 17).

Tensile tests were performed with a static electromechanical tensile testing machine (EZ Graph, Shimadzu Co., Ltd, Kyoto, Japan) equipped with a $5 \mathrm{kN}$ capacity load cell. All tests were conducted under displacement control at a strain rate of $5 \times 10^{-4} \mathrm{~s}^{-1}$. Two mini-specimens were examined for each test condition. The measurement uncertainty was estimated on the basis of recommendations of "Evaluation of measurement data-Guide to the expression of uncertainty in measurement" (Ref 18).

Microhardness measurements were taken on the mirrorpolished cross sections of the coatings by using a semiautomatic microhardness tester (MVK-E, Akashi Co., Ltd., Kanagawa, Japan) equipped with a Vickers indenter. For each spraying condition, at least 10 indentations were carried out with $0.5 \mathrm{kgf}$ loading for $15 \mathrm{~s}$.

\section{Heat Treatment}

Because of the possible application of Ti-6Al-4V coating to produce or repair structural elements, there is a demand to improve their mechanical properties to meet specified values given by standards and technical requirements. One approach is to perform heat treatments of as-received coatings. Ti-6Al-4V is a two-phase alloy comprising of both $\alpha$ - and $\beta$-phases at room temperature. Phase 
Table 1 Warm spray conditions for Ti-6Al-4V coatings

\begin{tabular}{|c|c|c|c|c|c|c|c|}
\hline \multirow[t]{2}{*}{ Condition ID } & \multirow{2}{*}{$\begin{array}{c}\text { Combustion } \\
\text { pressure (MPa) }\end{array}$} & \multicolumn{3}{|c|}{ Fuel/gas flow rates } & \multirow{2}{*}{$\begin{array}{l}\text { Spray distance } \\
(\mathrm{mm})\end{array}$} & \multirow{2}{*}{$\begin{array}{l}\text { Barrel length } \\
\quad(\mathrm{mm})\end{array}$} & \multirow{2}{*}{$\begin{array}{l}\text { Powder feed } \\
\text { rate }(\mathrm{g} / \mathrm{min})\end{array}$} \\
\hline & & Kerosene $\left(\mathrm{dm}^{3} / \mathrm{min}\right)$ & Oxygen $\left(\mathrm{m}^{3} / \mathrm{min}\right)$ & Nitrogen $\left(\mathrm{m}^{3} / \mathrm{min}\right)$ & & & \\
\hline LP-WS-0.5 & $0.9-1$ & 0.391 & 0.805 & 0.5 & 200 & 200 & 45 \\
\hline LP-WS-1.0 & & 0.347 & 0.714 & 1 & & & \\
\hline LP-WS-1.5 & & 0.303 & 0.623 & 1.5 & & & \\
\hline HP-WS-0.5 & $3.9-4.2$ & 0.380 & 0.780 & 0.5 & & & \\
\hline HP-WS-1.0 & & 0.335 & 0.685 & 1 & & & \\
\hline HP-WS-1.5 & & 0.290 & 0.590 & 1.5 & & & \\
\hline
\end{tabular}

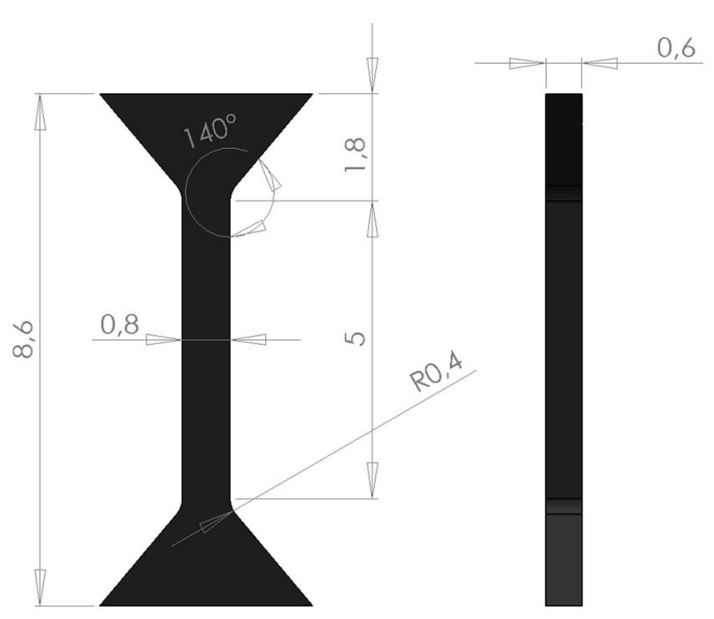

(a)



Fig. 1 Dimensions of miniature tensile specimens (a) and the method of cutting-off miniature specimens from deposited coatings (b)

composition as well as phase sizes and distribution can be tailored by heat treatment within certain limits to enhance a specific property or attain a range of strength levels. Annealing treatments are used to increase fracture toughness, creep resistance and ductility at room temperature.
Three heat treatments conditions recommended for Ti6Al-4V (Ref 19) were performed under vacuum taking into account the $\alpha \rightarrow \beta$ phase transformation temperature of $995{ }^{\circ} \mathrm{C}$ as schematically shown in Fig. 2. Before heat treatment, all the specimens were encapsulated in a quartz tube filled with argon in order to limit oxidation.

Mill annealing (Fig. 2a) is a general purpose heat treatment given to all mill products. However, it is not a full anneal, and it can leave traces of cold or warm working in the component microstructure. In this case, the Ti-6Al$4 \mathrm{~V}$ coatings were at first heated at $750{ }^{\circ} \mathrm{C}$ for $1 \mathrm{~h}$ and subsequently cooled to room temperature.

Recrystallization annealing (Fig. 2b) is used to improve ductility and fracture toughness. During recrystallization annealing, the alloy is heated into the upper end of the $\alpha \rightarrow \beta$ range (Ref 1 ), held for a period of time and then cooled down very slowly. In this study, the coatings were heated at $940{ }^{\circ} \mathrm{C}$ for $4 \mathrm{~h}$, then furnace cooled to $760{ }^{\circ} \mathrm{C}$ at a rate of $1{ }^{\circ} \mathrm{C} / \mathrm{min}$, further cooled to $480{ }^{\circ} \mathrm{C}$ at a rate about $5{ }^{\circ} \mathrm{C} / \mathrm{min}$ in the furnace, and finally cooled outside the furnace to room temperature.

Beta annealing (Fig. 2c) improves fracture toughness, fatigue strength and creep resistance. This treatment is done at temperatures above the $\alpha \rightarrow \beta$ phase transformation temperatures of the alloy. To avoid excessive grain growth, the anneal temperature should be only slightly higher than the $\beta$ transus temperature. The Ti-6Al-4V coatings were at first heated at $1025^{\circ} \mathrm{C}$ for $1 \mathrm{~h}$ and then cooled to room temperature at a rate higher than $85^{\circ} \mathrm{C} /$ min. Finally, subsequent annealing at $760{ }^{\circ} \mathrm{C}$ for $2 \mathrm{~h}$ followed by cooling outside the furnace was performed.

\section{Coatings Characterization}

Cross sections of coatings were obtained by embedding a specimen in cold-mounting resin followed by several steps of grinding with emery papers and subsequent polishing with diamond and alumina suspensions to $1 \mu \mathrm{m}$ finish. The microstructure of the coatings was investigated using backscattered electron (BSE) images in a scanning electron microscope (S-4700 FE-SEM, Hitachi Ltd., Tokyo, Japan). 



Fig. 2 Heat treatments performed for as-sprayed Ti-6Al-4V coatings: mill (a), recrystallization (b) and beta (c) annealing

In order to reveal the microstructure of the Ti-6Al-4V coatings, Kroll's reagent ( $\mathrm{Hf} 2$ vol.\%, $\mathrm{HNO}_{3} 4$ vol.\%, water bal.) was used and etch time was from about 20 to $40 \mathrm{~s}$.

Porosity of each sample was evaluated by image analysis performed on cross-sectional BSE micrographs (ImageJ: National Institutes of Health, Maryland, USA). For each spraying condition, at least ten images taken in the middle part of the coating was used.

Oxygen content of as-deposited coatings was analyzed by the inert gas fusion method (EMGA-620 W, Horiba Ltd., Kyoto, Japan). According to equipment manufacturer, a standard error of $1 \%$ was adopted for oxygen content measurement.

\section{Results \\ Effects of Nitrogen Flow Rate and Combustion Pressure on the Microstructure of Ti-6Al-4V Coatings}

Figure 3 shows typical cross-sectional SEM micrographs of the Ti-6Al-4V coatings for the three nitrogen flow rates by low- and high-pressure WS. In general, the cross sections observed with the BSE detection contain three ranges of grayscale contrast. The light gray regions represent the inner part of deposited particle, the dark gray regions usually represent oxides, which often are formed at the boundaries of the particles, and black regions indicate materials discontinuities appearing in the form of pores, microcracks and unbonded surfaces of deposited particles.

The coatings prepared with the lowest nitrogen flow rate $0.5 \mathrm{~m}^{3} / \mathrm{min}$ (Fig. 3a and d), which resulted in higher temperature, exhibited a dense microstructure, but the oxides at the particles boundaries can be clearly recognized. This phenomenon is especially evident for the low-pressure WS, with higher particle temperature and lower particle velocity compared to the high-pressure WS. Coatings formed with $1.0 \mathrm{~m}^{3} / \mathrm{min}$ nitrogen flow rate (Fig. $3 \mathrm{~b}$ and e) which resulted in lower particle temperatures were less dense and the oxides disappeared in the SEM micrographs. Furthermore, coatings deposited with a nitrogen flow rate of $1.5 \mathrm{~m}^{3} / \mathrm{min}$ (Fig. 3c and f) became more porous with less sign of oxidation.

Comparing the microstructure of the coatings by the low- and high-pressure WS, the coatings deposited by the high-pressure WS exhibit lower porosity and oxygen content. Quantitative analysis of porosity and oxygen content confirmed this conclusion drawn from SEM images as shown in Fig. 4. As in a previous study (Ref 11), the tradeoff relationship between density and purity of the coatings was found. However, the values of these features for 3-mm-thick coatings in this study were slightly higher than the values obtained for 0.5 -mm-thick coatings in a previous study (Ref 11). The reason is not very clear, and it will require further careful analysis. An optimal nitrogen flow rate for both systems may be chosen at $1.0 \mathrm{~m}^{3} / \mathrm{min}$, under which a good balance between porosity and oxygen content can be realized. As an important experimental result, the possibility to reduce porosity (from 7.3 to 1.9 vol.\%) and oxygen content (from 0.59 to 0.2 mass\%) of the formed 


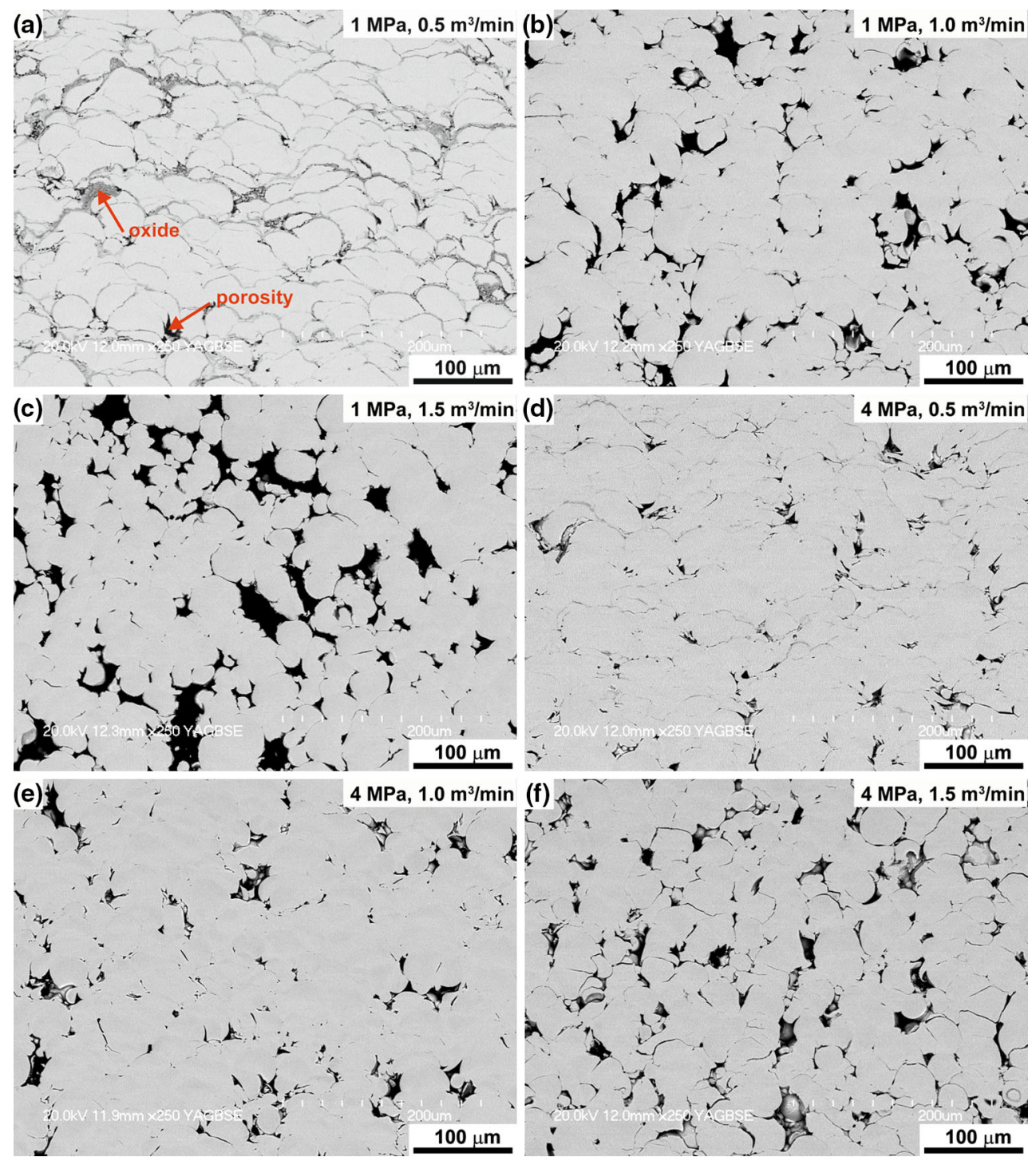

Fig. 3 Cross-sectional backscattered SEM images of Ti-6Al-4V coatings fabricated by low-(1 MPa, a-c) and high-(4 MPa, d-f) pressure warm spray system at three nitrogen flow rates of $0.5(\mathrm{a}, \mathrm{d}), 1.0(\mathrm{~b}, \mathrm{e})$ and $1.5(\mathrm{c}, \mathrm{f}) \mathrm{m}^{3} / \mathrm{min}$

Ti-6Al-4V coatings by the high-pressure WS for the same nitrogen flow rate of $1.0 \mathrm{~m}^{3} / \mathrm{min}$ was shown.

\section{Effects of Nitrogen Flow Rate and Combustion Pressure on the Mechanical Properties of Ti-6Al-4V Coatings}

Figure 5 shows the values of microhardness obtained for the Ti-6Al-4V coatings. In addition, the microhardness for bulk material annealed for $2 \mathrm{~h}$ at $750{ }^{\circ} \mathrm{C}$ in vacuum atmosphere is shown in the graph. The data clearly indicate that microhardness decreases with increasing nitrogen flow rate. The samples formed with the highest gas temperature and a nitrogen flow rate of $0.5 \mathrm{~m}^{3} / \mathrm{min}$ exhibited the highest values of microhardness for both coatings by the low and high WS (352 and 349 HV0.5, respectively).
These values are also greater than the microhardness determined for the bulk Ti-6Al-4V (322 HV0.5). The increase in microhardness for the as-sprayed deposits was attributed to both strain hardening that occurred during deposition and strengthening of the $\alpha$-phase by forming the so-called $\alpha$-case, which is a continuous layer of oxygen stabilized $\alpha$-phase formed around particles during in flight of the powder before deposition onto a substrate. On the other hand, the coatings formed with higher nitrogen flow rate $\left(1.0\right.$ and $\left.1.5 \mathrm{~m}^{3} / \mathrm{min}\right)$ exhibited lower values of microhardness compared to the bulk material, which was explained by the discontinuity of the microstructure of Ti$6 \mathrm{Al}-4 \mathrm{~V}$ coatings and the weak bonding between the deposited splats (Ref 11). For this case, the level of work hardening did not appear to be the main factor in determining microhardness. Moreover, there was also limited 


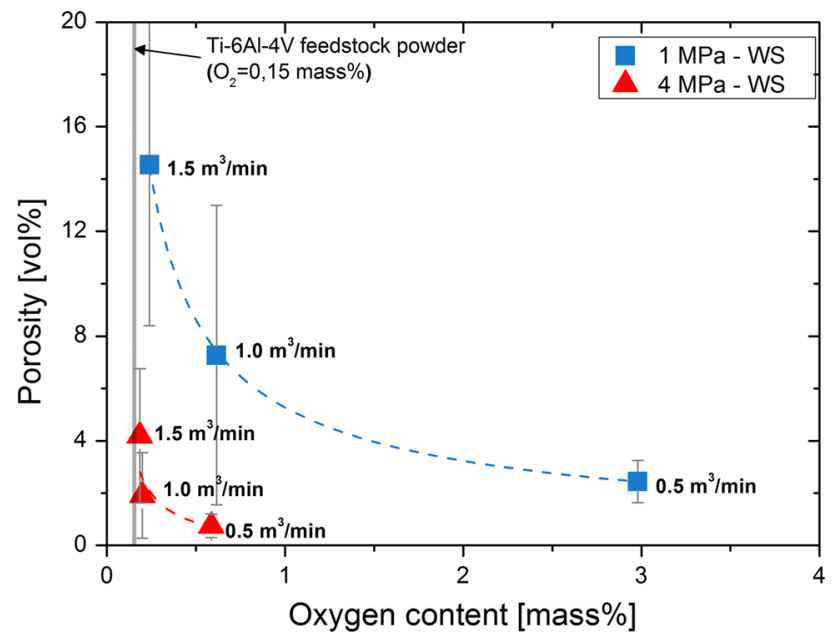

Fig. 4 Porosity and oxygen content for low- and high-pressure warm spray system (Ref 11)

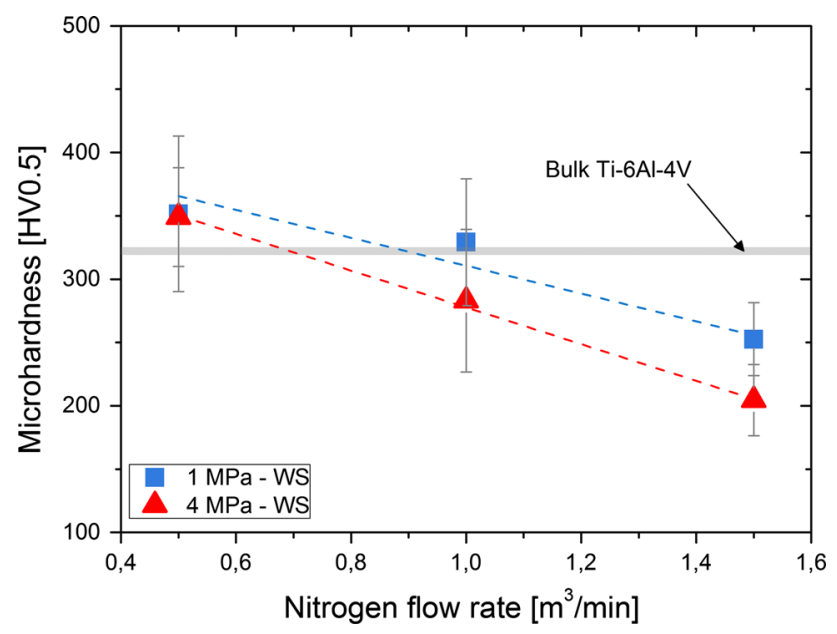

Fig. 5 Microhardness HV0.5 of coatings sprayed by low- and highpressure warm spray system as a function of nitrogen flow rate

influence of formed $\alpha$-case due to the lower oxygen content (see Fig. 4). To sum up, it was found that the coatings formed at high combustion pressure exhibited slightly lower microhardness in contrast to the coatings formed at low pressure, which was attributed to the lower oxygen contents. It is well known for titanium and it alloys that dissolved oxygen strengthens the $\alpha$-phase (Ref 1 ).

Figure 6 shows the ultimate tensile strength, Young's modulus and elongation to failure of as-sprayed coatings determined by the uniaxial tensile test of mini-specimens as a function of the nitrogen flow rate. Figure 6 shows that both the ultimate tensile strength (Fig. 6a) and the Young's modulus (Fig. 6b) decreased with increasing the nitrogen flow rate. This effect is mainly attributed to the increase in discontinuities (Fig. 7a and b), which reduce the effective cross-sectional area of the specimens. Since the ultimate tensile strength is inversely proportional to the cross-
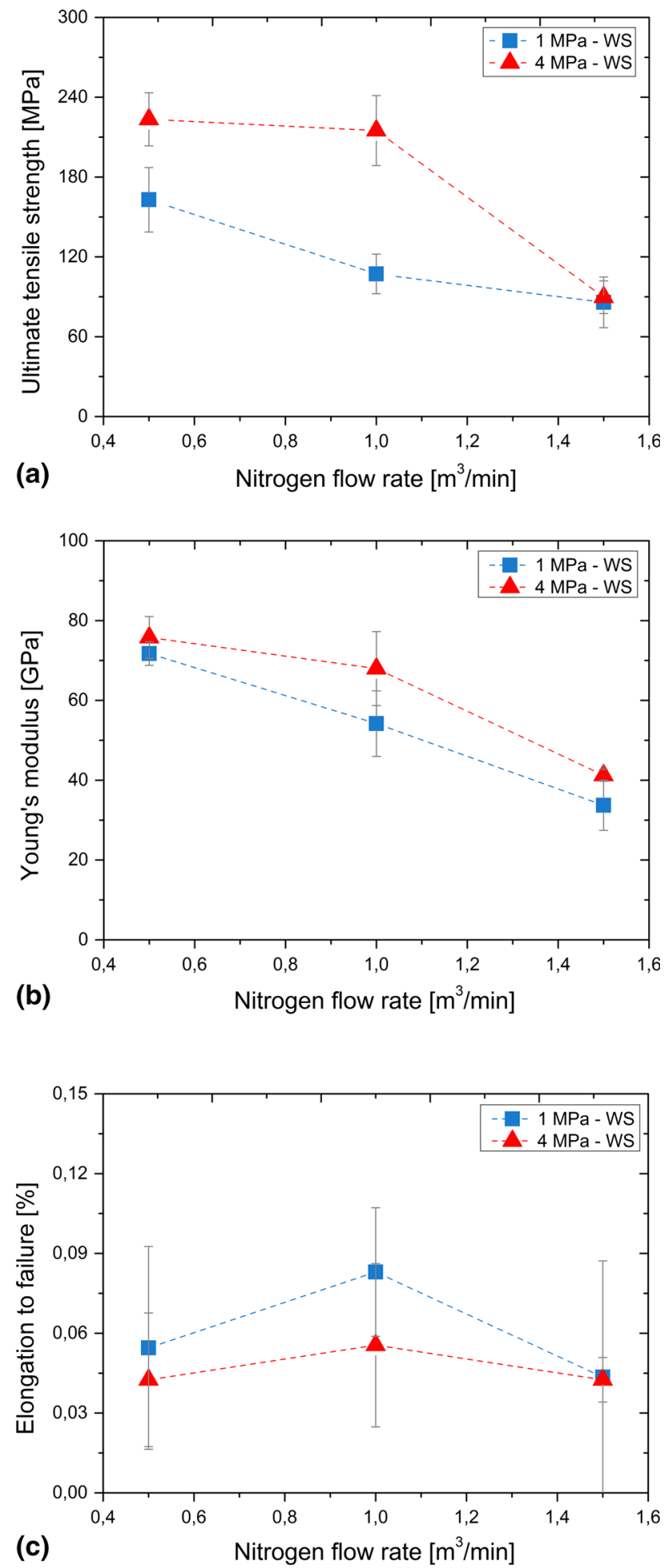

Fig. 6 Tensile strength (a), Young's modulus (b) and elongation to failure (c) of Ti-6Al-4V coatings formed by low- and high-pressure warm spray system as a function of nitrogen flow rate

sectional area of a specimen, the reduction in the effective load bearing area due to the increase in discontinuities causes premature failure (Fig. 7a). Furthermore, the 
increase in discontinuities of the microstructure in the form of pores and un-bonded interfaces made the miniature specimen more susceptible to applied stress, and therefore, the Young's modulus is reduced (Fig. 7b).
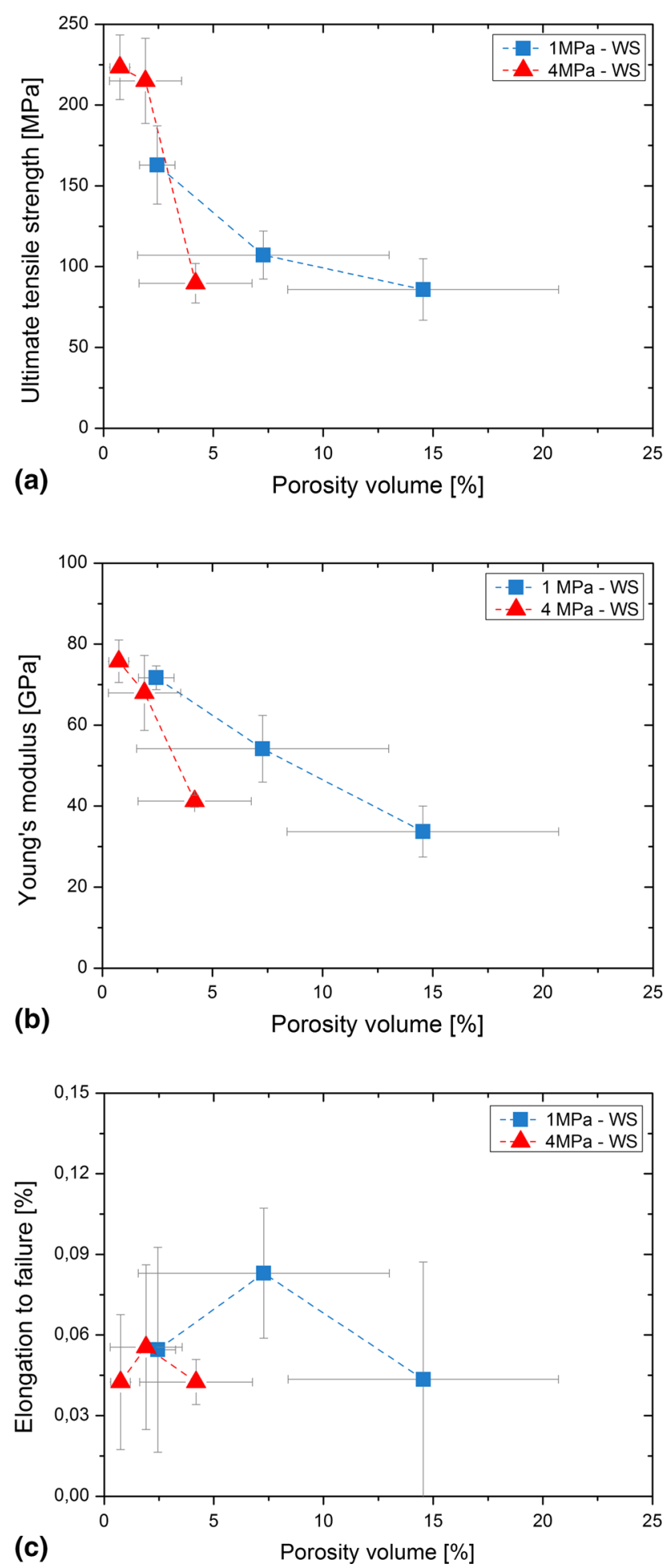

Fig. 7 Tensile strength (a), Young's modulus (b) and elongation to failure (c) of Ti-6Al-4V coatings formed by low- and high-pressure warm spray system as a function of porosity
Figure 6(c) and 7(c) show the elongation to failure as a function of the nitrogen flow and porosity. The presence of discontinuities of the microstructure in the form of pores and un-bonded interfaces (for $1.5 \mathrm{~m}^{3} / \mathrm{min}$ nitrogen flow rates) and oxides (for $0.5 \mathrm{~m}^{3} / \mathrm{min}$ nitrogen flow rates) caused low deformability (Fig. 7c). In spite of the brittle character of the fracture and relatively high scatter of results, the best deformability was found for the optimal content of both porosity and oxides volume (for $1.0 \mathrm{~m}^{3} /$ min nitrogen flow rates) (compare with Fig. 4). Similar negative effects of porosity on the mechanical properties of cold-sprayed Ti-6Al-4V coatings were found by Vo et all (Ref 13). They reported that the tensile strength of low porous He-sprayed coatings was nearly three times higher compared with $\mathrm{N}_{2}$-sprayed coatings. The average porosity levels were 0.3 and 8.1 vol.\% for all $\mathrm{He}$ - and $\mathrm{N}_{2}$-sprayed coatings (including as-sprayed and annealed), respectively.

Figure 8 shows SEM micrographs of fracture surfaces of the mini-specimens after the failure in tensile tests for Ti-6Al-4V coatings by high-pressure WS. For all Ti-6Al-4V coatings at as-sprayed conditions, brittle fracture through particles' boundaries was observed without any signs of plastic deformation. The fracture surface was smooth with deformed particle shapes which indicate low bonding strength between deposited splats. It is evident that coatings formed at the lowest nitrogen flow rate $\left(0.5 \mathrm{~m}^{3} / \mathrm{min}\right)$ had relatively high particle temperature of around $1250 \mathrm{~K}$ (Ref 11). It can be concluded that mechanical properties of the as-sprayed coatings are mainly determined by mechanical interlocking between deformed particles. Therefore, strength properties of the as-sprayed coatings were relatively low, and plasticity was quite poor.

\section{Effects of Heat Treatment on the Microstructure of Ti-6Al-4V Coatings}

Figure 9 shows cross-sectional SEM images of the assprayed and heat-treated $4 \mathrm{MPa}$ WS Ti-6Al-4V coatings at the three nitrogen flow rates of $0.5,1.0$ and $1.5 \mathrm{~m}^{3} / \mathrm{min}$. Because of several values for particle velocity and temperature, noticeable difference in the microstructure of assprayed Ti-6Al-4V coatings was found and described in detail in the previous part of Ref 11 . The main conclusion was that there is a trade-off relationship between porosity and oxygen content as a function of the nitrogen flow rate and, consequently, particle temperature.

Quantitative analysis of porosity and related parameters (mean size of pore and relative number of pores) is presented in Table 2. The number of pores in the region of interest for the specimen after heat treatment was calculated in relation to the as-received coatings. Thus, the number of pores at the as-sprayed condition was 1 . Values lower than 1 indicate a decrease in the number of pores, 

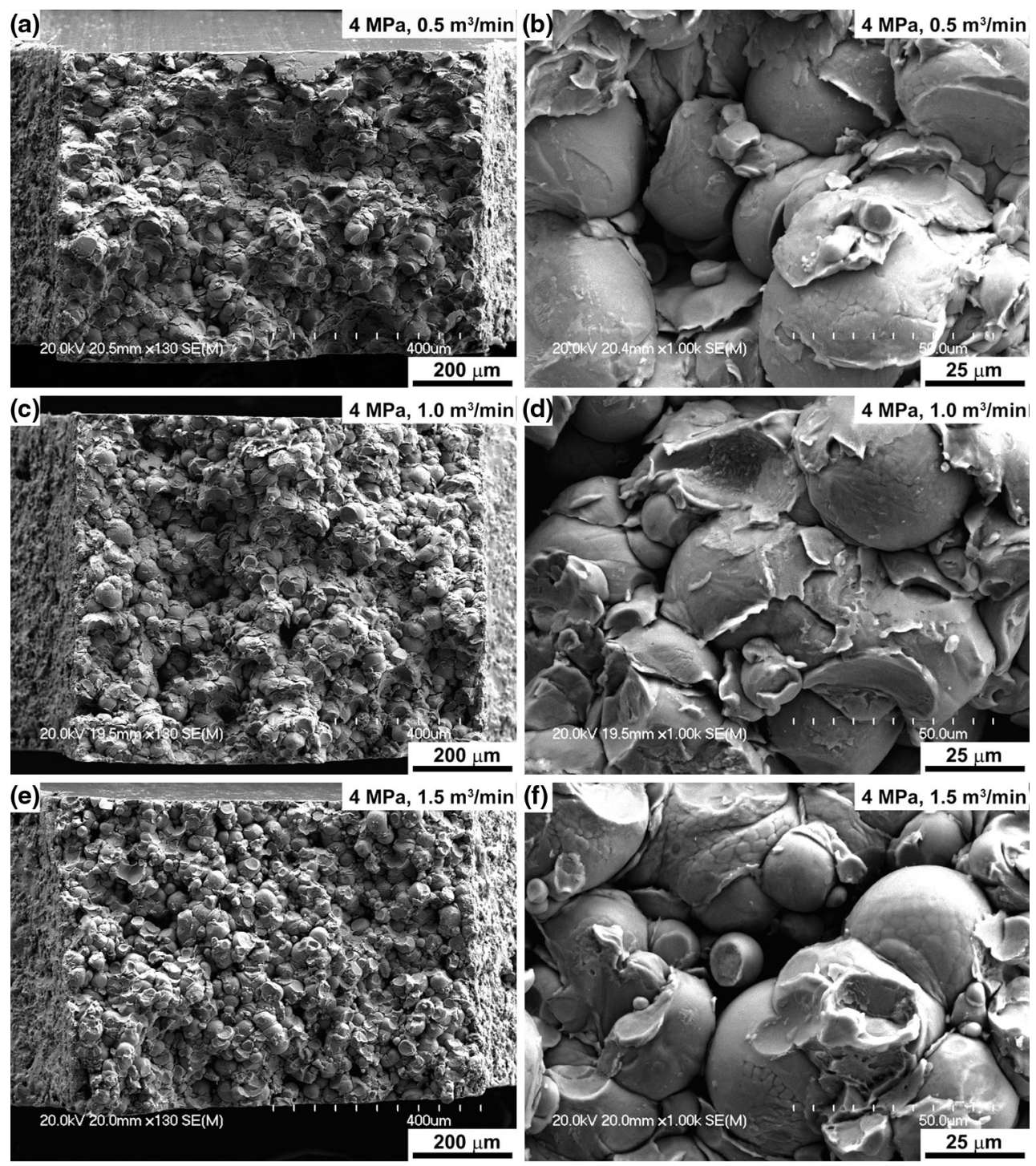

Fig. 8 Fracture surfaces of Ti-6Al-4V coatings by high-pressure warm spray at three nitrogen flow rates of $0.5(\mathrm{a}, \mathrm{b}), 1(\mathrm{c}, \mathrm{d})$ and $1.5 \mathrm{~m}^{3} / \mathrm{min}(\mathrm{e}$, f)

and values higher than 1 indicate increase in the number of pores, respectively.

It should be noted that for the as-sprayed and heattreated coatings, the pore distribution was relatively homogenous throughout the coating cross sections; hence, tamping effect, which should give higher porosity in the surface layer, was not noticed. For the mill annealed coatings $\left(750{ }^{\circ} \mathrm{C}, 1 \mathrm{~h}\right)$, the porosity level remained relatively similar to the as-sprayed coatings, except for a slight increase in porosity for the coating formed at $0.5 \mathrm{~m}^{3} / \mathrm{min}$ (from $0.7 \pm 0.4$ to $1.3 \pm 1 \%$ ), which could be an effect of measuring accuracy and relatively high scattering of the porosity. On the other hand, recrystallization annealing resulted in significant coalescence and spheroidization of existing pores, which was confirmed by an increase in average pore size, while their number was reduced
(Table 5). It was found that neck growth took place, increasing the metallurgically bonded region and most interfaces between deposited particles disappeared as shown in Fig. 9(c), (g), and (k). Similar effects were found for the coatings after beta annealing $\left(1025{ }^{\circ} \mathrm{C}, 1 \mathrm{~h}\right)$ was performed above $\alpha \rightarrow \beta$ transus temperature as shown in Fig. 9, 10(d), (h), and (1). It should be noted that heat treatments performed at such high temperatures (recrystallization and beta annealing) caused a $30-40 \%$ decrease in porosity regardless of the warm spraying condition. Similar phenomenon was found for several CS coatings such as Ti6-Al-4V (Ref 12), Ti (Ref 20) or Inconel 718 (Ref 21); however, there is no clear explanation of this phenomenon. For the present WS coatings, a decrease in porosity is supposed to be primarily caused by complete reconstruction of strongly deformed and strain hardened as-sprayed 


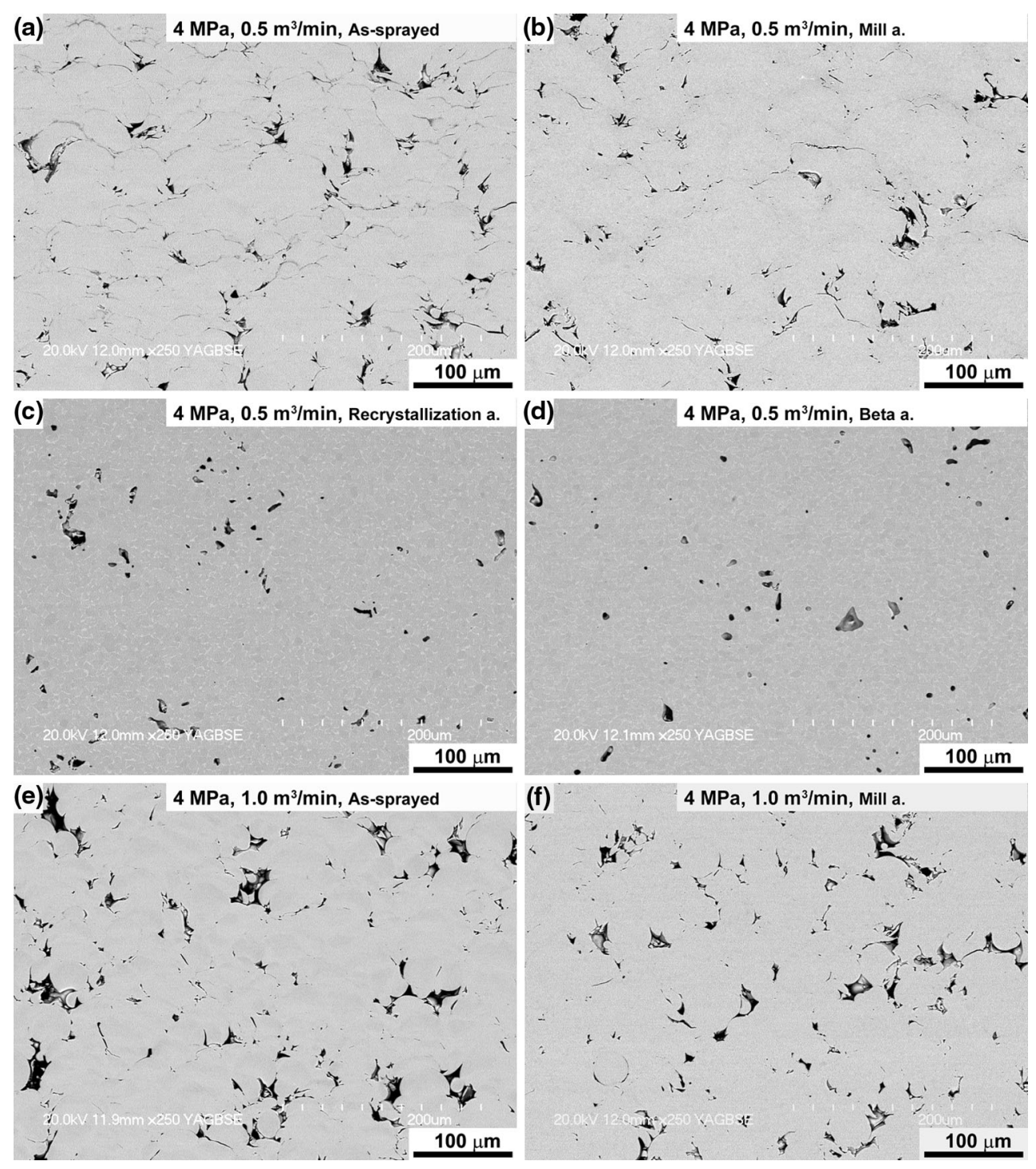

Fig. $9 \mathrm{SEM} / \mathrm{BSE}$ cross-sectional micrographs of as-sprayed and heat-treated Ti-6Al-4V coatings fabricated at three nitrogen flow rates of $0.5,1$ and $1.5 \mathrm{~m}^{3} / \mathrm{min}$

Table 2 Porosity, average size of pores and relative number of pores for as-sprayed and heat-treated Ti-6Al-4V coatings by high-pressure warm spray

\begin{tabular}{|c|c|c|c|c|c|c|c|c|c|}
\hline \multirow{2}{*}{$\begin{array}{l}\text { Parameter } \\
\text { Nitrogen flow rate }\left(\mathrm{m}^{3} / \mathrm{min}\right)\end{array}$} & \multicolumn{3}{|c|}{ Porosity volume (vol.\%) } & \multicolumn{3}{|c|}{ Average size of pores $(\mu \mathrm{m})$} & \multicolumn{3}{|c|}{ Relative no. of pores } \\
\hline & 0.5 & 1.0 & 1.5 & 0.5 & 1.0 & 1.5 & 0.5 & 1.0 & 1.5 \\
\hline As-spray & $0.7 \pm 0.4$ & $2 \pm 1.3$ & $4.4 \pm 2.4$ & $1.7 \pm 0.7$ & $5.2 \pm 2.8$ & $8.3 \pm 3$ & 1 & 1 & 1 \\
\hline Mill annealing & $1.3 \pm 1$ & $2.1 \pm 1.2$ & $4.5 \pm 1.6$ & $2.9 \pm 1.3$ & $5.2 \pm 2.4$ & $10.1 \pm 2.5$ & 1.02 & 0.98 & 0.88 \\
\hline Recrystallization annealing & $0.5 \pm 0.3$ & $1.6 \pm 1.1$ & $3.4 \pm 2.1$ & $6.7 \pm 2.1$ & $13.3 \pm 9.3$ & $17 \pm 10.2$ & 0.22 & 0.4 & 0.4 \\
\hline Beta annealing & $0.5 \pm 0.5$ & $1.2 \pm 1.1$ & $3.8 \pm 1.9$ & $10.1 \pm 8.2$ & $9.6 \pm 4.5$ & $14 \pm 6.7$ & 0.13 & 0.31 & 0.51 \\
\hline
\end{tabular}

microstructure due to static recovery followed by static recrystallization processes.

Figure 10 shows SEM images of etched cross sections of the Ti- $6 \mathrm{Al}-4 \mathrm{~V}$ coatings in the as-sprayed condition and after heat treatment. It was difficult to obtain a distinct microstructure of the as-sprayed coatings due to severe plastic deformation of the powder particles. However, a weak relief of a very fine microstructure was revealed (Fig. 10a, e, and i). Further increase in etching time resulted in an over-etching of the particle interfaces. The 


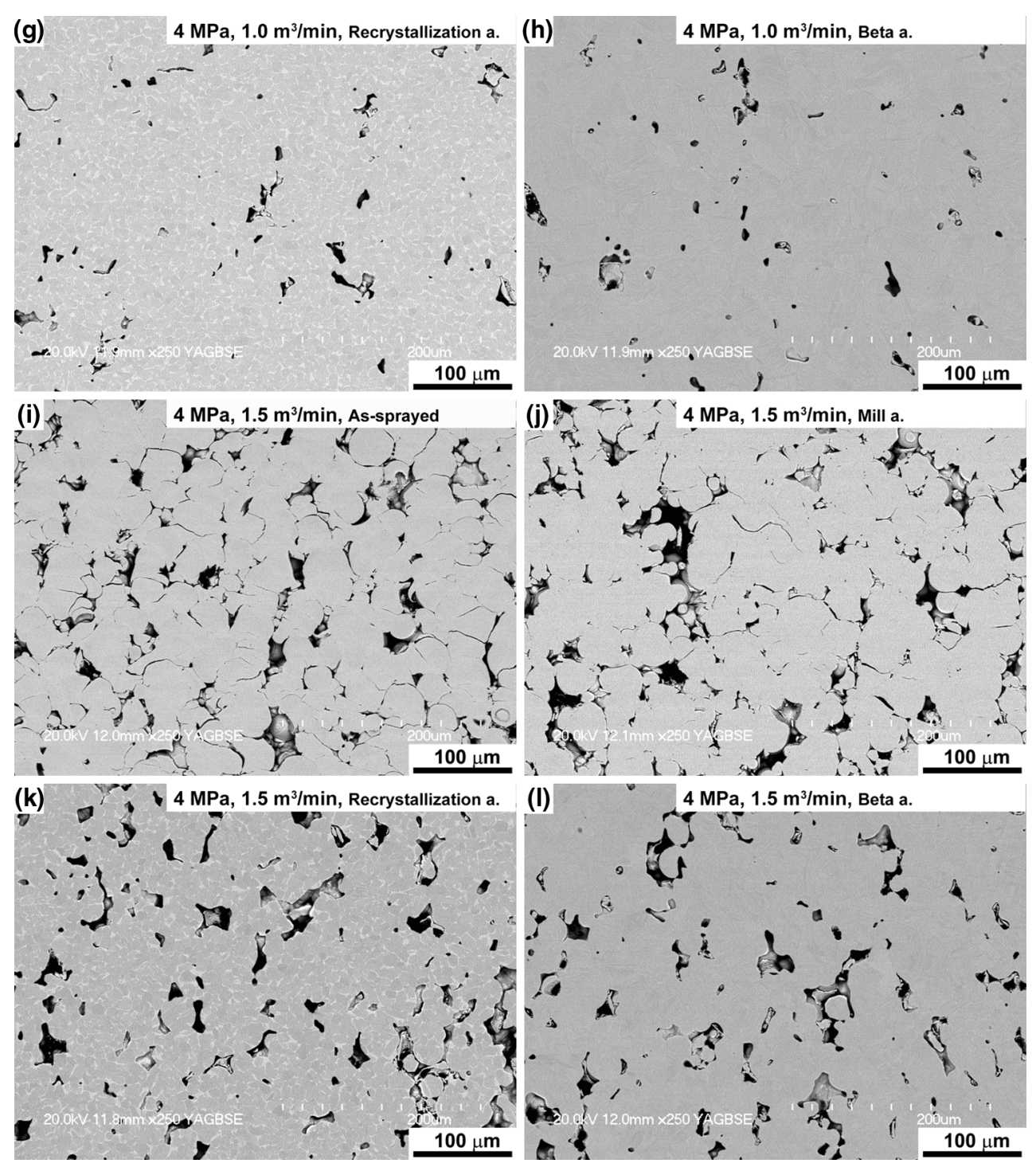

Fig. 9 continued

particle bonding boundary was preferentially etched, which implied that the dominant "bonding mechanism" might be mechanical interlocking.

The performed heat treatments resulted in changes of composition and distribution of $\alpha$ - and $\beta$-phases. After mill annealing, fine region of $\beta$-phase was found in $\alpha$ matrix for all samples regardless of the WS conditions. Interestingly, sometimes it is possible to distinguish former shapes of splats (arrow in Fig. 9f) which primarily consist of the $\alpha$-phase, caused by a high oxygen content especially at the particles boundaries in a form of oxides. This element is classified as an $\alpha$ stabilizer, and it prevented the formation of the $\beta$-phase in oxygen-rich areas. Recrystallization annealing resulted in a microstructure that consists of an equiaxed $\alpha$ and an intergranular $\beta$-phase. Beta annealing performed above the $\alpha \rightarrow \beta$ transus temperature $\left(T \alpha \rightarrow \beta_{\text {Ti-6-Al-4V }}=995^{\circ} \mathrm{C}\right)$ resulted in a microstructure composed of lameral $\alpha$ and intergranular $\beta$-phase for coatings with lower oxygen content $\left(1.0\right.$ and $1.5 \mathrm{dm}^{3} / \mathrm{min}$ nitrogen flow rate). However, for the coating with the nitrogen flow rate $0.5 \mathrm{dm}^{3} / \mathrm{min}$, the microstructure consists of equiaxed $\alpha$ and intergranular $\beta$-phase, similar to the microstructure after recrystallization annealing. This effect was probably due to the higher oxygen content (0.59 mass\%), which increases the $\alpha \rightarrow \beta$ transus temperature, and thus, the sample remained in the $\alpha$-phase region (Ref 2), even it was treated at $1025{ }^{\circ} \mathrm{C}$.

Based on these observations, it was concluded that heat treatment has two main contributions to the coating microstructure: firstly, elimination of anisotropy in the microstructure and secondly healing-up of the incomplete interfaces between deposited particles. Therefore, improved mechanical properties are expected after the post-spray heat treatment. 

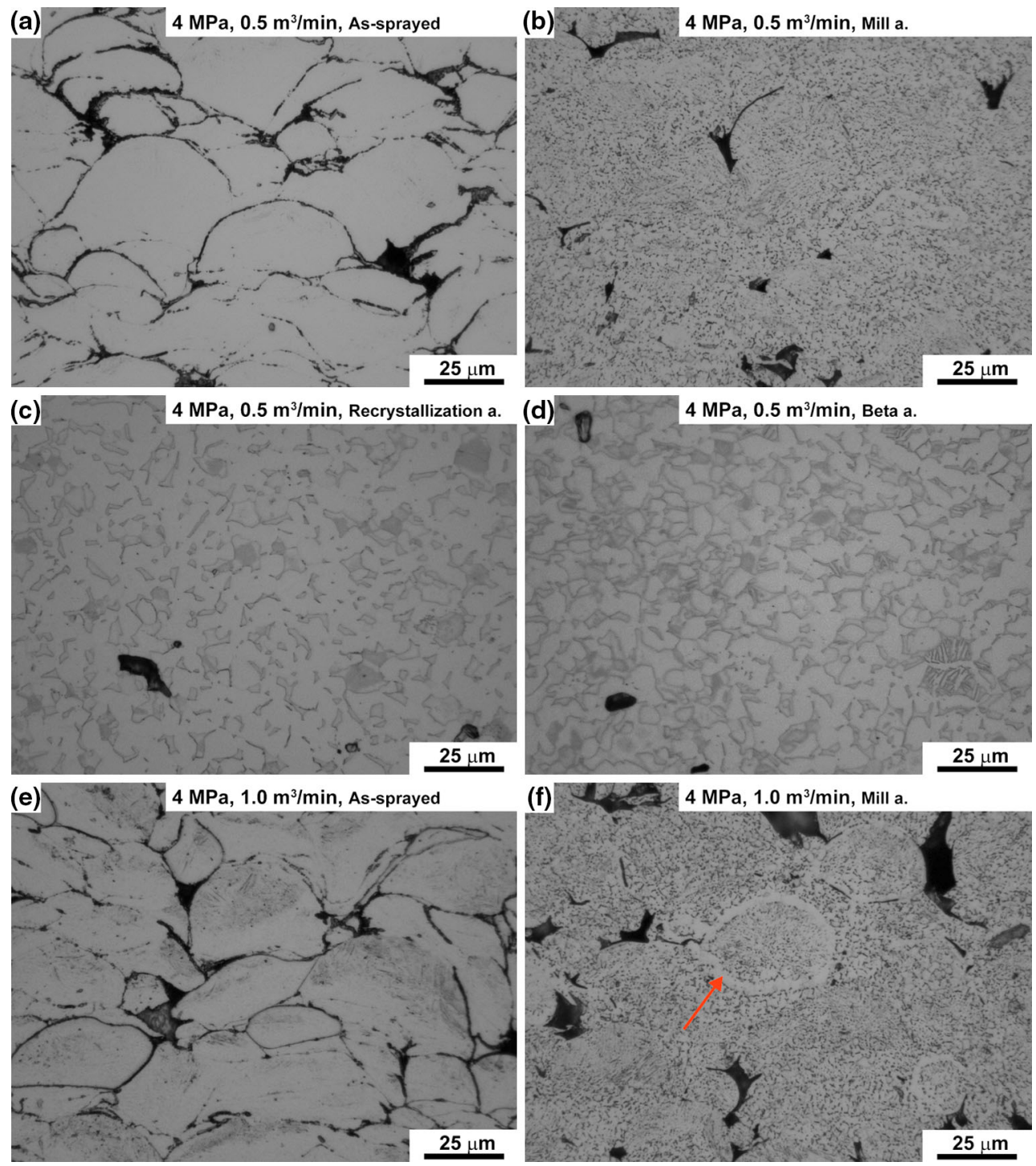

Fig. 10 Cross-sectional etched micrographs of as-sprayed and heat-treated Ti-6Al-4V coatings fabricated at three nitrogen flow rates of $0.5,1$ and $1.5 \mathrm{~m}^{3} / \mathrm{min}$

\section{Effects of Heat Treatment on the Mechanical Properties of Ti-6Al-4V Coatings}

Values of microhardness of as-sprayed and heat-treated Ti-6Al-4V coatings are plotted in Fig. 11. The differences in microhardness in the as-sprayed coatings persisted for the heat-treated samples. The highest microhardness was measured for the coatings deposited at the lowest nitrogen flow rate, and the values gradually decreased with increasing nitrogen flow rate (Ref 11). After heat treatment, however, a noticeable decrease in microhardness was found for the samples after mill annealing. One explanation for this effect is static recovery and possibly static recrystallization activated at elevated temperatures. This phenomenon is well known and has been reported in many CS coatings such as $\mathrm{Ti}$ (Ref 22), $\mathrm{Cu}$ (Ref 23), $\mathrm{Cu}-4 \mathrm{Cr}-2 \mathrm{Nb}$ (Ref 24), 304 stainless steel (Ref 25), Inconel 718 (Ref 21) and Ti-6Al$4 \mathrm{~V}$ slightly (Ref 12). Interestingly, a noticeable increase in microhardness was observed for the samples treated by recrystallization and beta annealing. It is assumed that it is primarily caused by diffusion of oxygen from the interface between particles into the titanium matrix, strengthening the $\alpha$-phase. This hypothesis could be confirmed by the fact that this effect was most pronounced for sample with the highest oxygen level of 0.59 mass $\%$. Additionally, it is believed that the increase in microhardness occurred after recrystallization and beta annealing is a consequence of particle interfaces healingup owing to the formation of metallic bonding thorough 
Fig. 10 continued


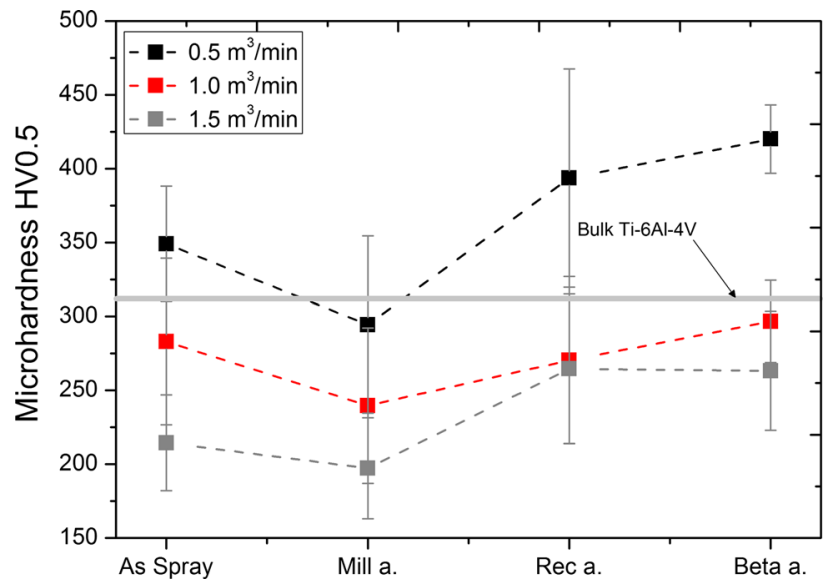

Fig. 11 Microhardness HV0.5 of the as-sprayed and heat-treated coatings Ti-6Al-4V coatings fabricated at three nitrogen flow rates of $0.5,1.0$ and $1.5 \mathrm{~m}^{3} / \mathrm{min}$

solid-state diffusion as discussed above. Relatively, large standard deviations were due to the indenter interaction with the weak bonded particles, which were detached from the surrounding deposit and resulted in reduced resistance against indentation (Ref 11).

Tensile tests were carried out for all coatings after mill and recrystallization annealing and additional tests after beta annealing for the coating with optimal porosity and oxygen content $\left(1.0 \mathrm{~m}^{3} / \mathrm{min}\right)$. The data obtained for assprayed and heat-treated Ti-6Al-4V coatings deposited at various nitrogen flow rates are summarized in Table 3, and corresponding engineering stress-strain curves are plotted in Fig. 12. In addition, fracture surfaces of the mini tensile specimens are presented in Fig. 13. While as-sprayed coatings, regardless of spraying conditions, exhibited very low ductility $\left(\varepsilon_{\mathrm{PL}}<0.1 \%\right)$, the coatings became more ductile after heat treatment (Fig. 12). This effect is most pronounced for the coatings with relatively low oxygen content sprayed at 1.0 (Fig. 12b) and $1.5 \mathrm{~m}^{3} / \mathrm{min}$ (Fig. 12c) nitrogen flow rate $(0.2$ and 0.18 mass $\%$ oxygen, respectively), which should be explained by better interparticle bonding as a result of sintering at the high temperatures. The same phenomenon enhanced tensile strength and 
Table 3 Mechanical properties determined by tensile test of mini-specimens for as-received and heat-treated Ti-6A-4V coatings and bulk Ti$6 \mathrm{Al}-4 \mathrm{~V}$

\begin{tabular}{|c|c|c|c|c|c|c|}
\hline $\begin{array}{l}\text { Nitrogen flow } \\
\text { rate }\left(\mathrm{m}^{3} / \mathrm{min}\right)\end{array}$ & Coating condition & $\begin{array}{l}\text { Young's } \\
\text { modulus } \\
E(\mathrm{GPa})\end{array}$ & $\begin{array}{l}\text { Yield strength } \\
R_{0,2}(\mathrm{MPa})\end{array}$ & $\begin{array}{c}\text { Ultimate tensile } \\
\text { strength UTS }(\mathrm{MPa})\end{array}$ & $\begin{array}{l}\text { Plastic elongation } \\
\text { to failure } \varepsilon_{\mathrm{pl}}(\%)\end{array}$ & $\begin{array}{l}\text { Total elongation } \\
\text { to failure } \varepsilon_{\mathrm{f}}(\%)\end{array}$ \\
\hline \multirow[t]{4}{*}{0.5} & As-spray LP-WS & $72 \pm 3$ & $\ldots$ & $163 \pm 24$ & $0.05 \pm 0.04$ & $0.26 \pm 0.09$ \\
\hline & As-spray HP-WS & $76 \pm 5$ & $\ldots$ & $223 \pm 20$ & $0.04 \pm 0.03$ & $0.33 \pm 0.06$ \\
\hline & Mill annealing & $94 \pm 12$ & $\ldots$ & $486 \pm 49$ & $0.05 \pm 0.01$ & $0.54 \pm 0.16$ \\
\hline & Recrystallization anealing & $100 \pm 5$ & $\ldots$ & $807 \pm 107$ & $0.08 \pm 0.07$ & $0.89 \pm 0.28$ \\
\hline \multirow[t]{5}{*}{1.0} & As-spray LP-WS & $54 \pm 8$ & $\cdots$ & $107 \pm 15$ & $0.08 \pm 0.02$ & $0.25 \pm 0.12$ \\
\hline & As-spray HP-WS & $68 \pm 9$ & $\cdots$ & $215 \pm 26$ & $0.06 \pm 0.03$ & $0.35 \pm 0.12$ \\
\hline & Mill annealing & $77 \pm 1$ & $528(a)$ & $533 \pm 5$ & $0.28 \pm 0.32$ & $0.93 \pm 0.31$ \\
\hline & Recrystallization anealing & $98 \pm 7$ & $705 \pm 5$ & $824 \pm 110$ & $2.22 \pm 0.47$ & $2.84 \pm 0.63$ \\
\hline & Beta annealing & $91 \pm 3$ & $725 \pm 16$ & $820 \pm 15$ & $3.04 \pm 0.46$ & $3.93 \pm 0.47$ \\
\hline \multirow[t]{4}{*}{1.5} & As-spray LP-WS & $34 \pm 6$ & $\cdots$ & $86 \pm 19$ & $0.04 \pm 0.04$ & $0.35 \pm 0.27$ \\
\hline & As-spray HP-WS & $40 \pm 1$ & $\cdots$ & $88 \pm 12$ & $0.04 \pm 0.01$ & $0.25 \pm 0.05$ \\
\hline & Mill annealing & $49 \pm 3$ & $\cdots$ & $247 \pm 1$ & $0.09 \pm 0.05$ & $0.56 \pm 0.06$ \\
\hline & Recrystallization anealing & $83 \pm 7$ & $586 \pm 6$ & $646 \pm 33$ & $1.33 \pm 0.63$ & $2.07 \pm 0.66$ \\
\hline \multicolumn{2}{|c|}{ Bulk Ti-6Al-4V(b) } & $105-120(c)$ & $\min 759(b)$ & $\min 828(b)$ & $\ldots$ & $\min 10(b)$ \\
\hline
\end{tabular}

(a) Only for 1 specimen

(b) According to Ref 26

(c) According to http://matweb.com

Young's modulus for all the heat-treated samples compared to the as-received materials. Such improvement of mechanical properties after annealing is generally consistent with the data of tensile strength determined for Ti-6Al$4 \mathrm{~V}$ coatings prepared by CS (Ref 3,21) and LPPS (Ref 14) as well as for other CS coatings such as 304 stainless steel (Ref 25) and $\mathrm{Cu}-4 \mathrm{Cr}-2 \mathrm{Nb}$ (Ref 24). However, decrease in tensile strength was reported for some CS coatings, such as $\mathrm{Ti}(\operatorname{Ref} 22), \mathrm{Al}(\operatorname{Ref} 26)$ and Inconel 718 (Ref 21).

SEM images of fracture surfaces of mini tensile specimens cut out of WS coating after heat treatments are shown in (Fig. 13). Despite the fact that the as-received coatings exhibited brittle interparticle fracture regardless of the spraying conditions (Fig. 8), fracture surfaces after heat treatments revealed features that are consistent with the observed increase in ductility. For the coatings after mill annealing, dimples were observed in very limited areas of particles interface (Fig. 13a). This tendency was most pronounced for the coatings with relatively low level of oxygen content formed at 1.0 and $1.5 \mathrm{~m}^{3} / \mathrm{min}$ nitrogen flow rate $(0.2$ and 0.18 mass $\%$, respectively) as shown in Fig. 13(c) and (f). Generally, dimpled regions were larger for the coatings after recrystallization annealing (Fig. 13d and $\mathrm{g}$ ); however, the transgranular cleavage fracture appeared for the coating with the highest oxygen content $(0.59$ mass\%) as presented in Fig. 13(b). It is well known for titanium and its alloys that an increasing oxygen level strengthens the $\alpha$-phase and changes the deformation behavior from wavy to the planar slip mode and the propensity for twining declines rapidly. This change in deformation behavior is accompanied by a significant reduction in ductility which is consistent with the results of elongation to failure determined for coatings after recrystallization annealing as shown in Fig. 12(a) and 13(b).

While plastic elongation to failure for samples with relatively low oxygen level $(0.2$ and 0.18 mass $\%$ for coatings by 1.0 and $1.5 \mathrm{~m}^{3} / \mathrm{min}$ nitrogen flow rate, respectively) was in the range of $1.3-3.0 \%$, for the coating by $0.5 \mathrm{~m}^{3} / \mathrm{min}$ nitrogen flow rate elongation was lower than $0.1 \%$ due to the strengthening oxygen effect. Almost completely dimpled fracture surfaces were revealed for the coatings by $1.0 \mathrm{~m}^{3} / \mathrm{min}$ after recrystallization and beta annealing, which reflect in their relatively high value of elongation to failure.

Based on SEM images, the plastically failed area on the fracture surfaces of mini tensile specimens was calculated for the coating as $1.0 \mathrm{~m}^{3} / \mathrm{min}$ (Fig. 14). For the as-sprayed coatings, the dimpled area was so slight as to be unnoticeable. However, there was a clear increase in the area of plastic fracture for the coatings after heat treatment (Table 4). Lack of plastic elongation for the as-sprayed coating by $1.0 \mathrm{~m}^{3} / \mathrm{min}$ (Fig. 12b) was confirmed by no plastic features on the mini-specimen fracture. After mill annealing, there was a significant increase in area of plastic 

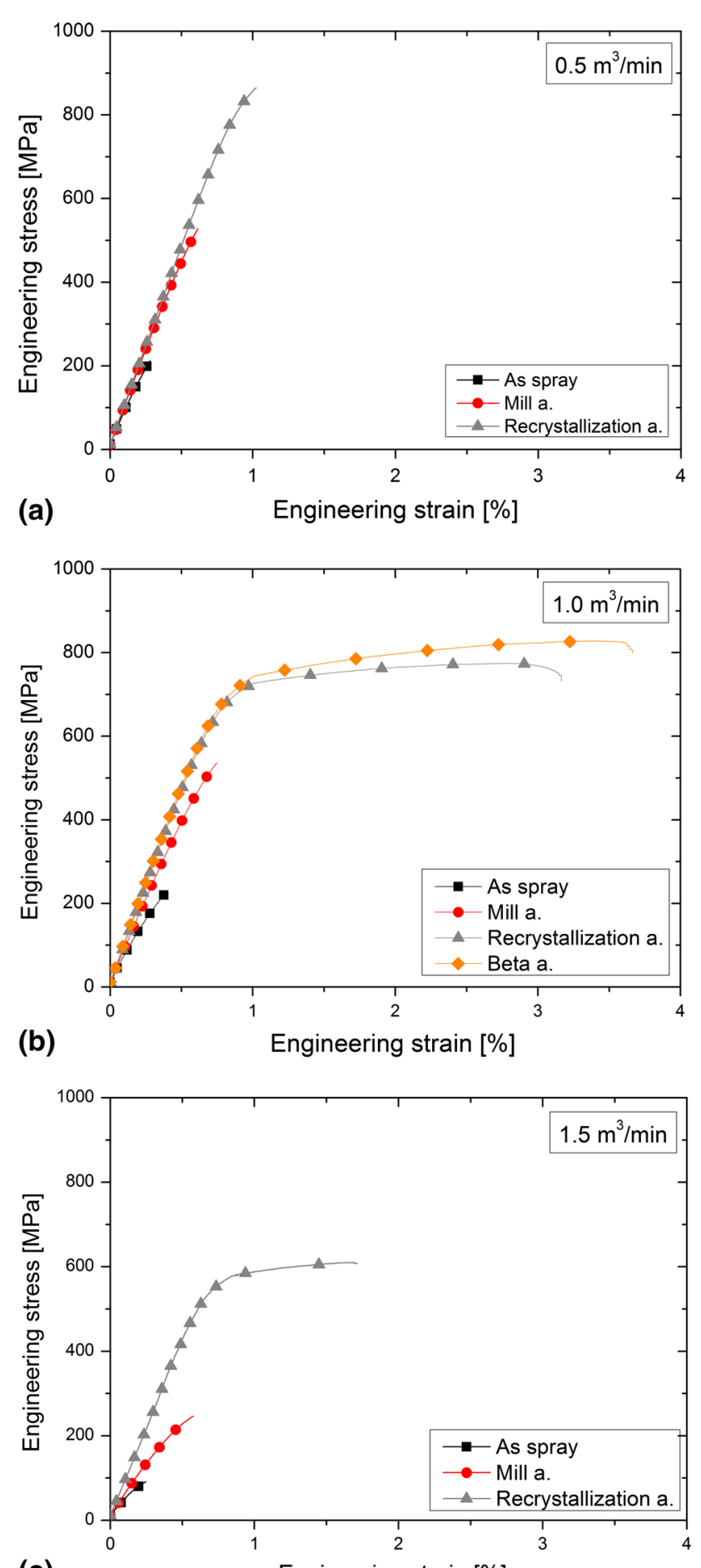

(c)

Engineering strain [\%]

Fig. 12 Engineering stress-strain curves for as-sprayed and heattreated Ti-6Al-4V coatings fabricated at three nitrogen flow rates of 0.5 (a), 1.0 (b) and $1.5 \mathrm{~m}^{3} / \mathrm{min}$ (c)

fracture to above $31 \%$; however, it did not significantly increase elongation to failure, which was only $0.28 \pm 0.32$, probably due to oxidation of particles. Only in the specimens after recrystallization and beta annealing, increase in bonding between deposited particles resulted in increase in plastic fracture area (above $50 \%$ of the whole fracture area) on the mini tensile specimen cross-sectional area, which considerably increases the plastic elongation of miniature tensile specimens $(2.22 \pm 0.47$ and $3.04 \pm 0.46 \mathrm{vol} . \%$, respectively).

\section{Discussion}

The higher values of tensile strength and Young's modulus for the coatings formed by high-pressure WS (Table 3) may be related to the increase in the particle velocity compared to the low-pressure WS. The particle velocity at which deposition takes place is known as critical velocity. It is a function of temperature, yield strength of the material and powder size (Ref 27, 28). When the particle velocity exceeds a critical value, the phenomenon called adiabatic shear instability appears (Ref 29,30 ), which is caused by the dominance of thermal softening over work hardening in the interfacial region of sprayed particles and the substrate. In this region, temperature can approach and even reach the melting point of the material, thus leading to viscoelastic material flow and formation of conformal interface and metallurgical bonding.

Figure 15 shows numerically calculated particle velocity and temperature at substrate position of $200 \mathrm{~mm}$ downstream the barrel for the low- and high-pressure WS (Ref 11), as well as the critical velocity for $25-\mu \mathrm{m}$ Ti-6Al$4 \mathrm{~V}$ particles. The bonding criterion was calculated with the use of a semiempirical expression (1) (Ref 27). The nomenclature, parameters and its values used for calculations are defined in Table 5. If particle velocity and temperature can be plotted above this line, the deposition fulfills the bonding criteria. It was found that almost all deposition parameters in this study, except low-pressure WS coating deposited at nitrogen flow rate of $0.75 \mathrm{~m}^{3} / \mathrm{min}$, (particle temperature and velocity) for both low- and highpressure WS coatings exceed the critical value of the velocity.

$v_{\text {crit }}=\sqrt{\frac{4 F_{1} \sigma_{\mathrm{UTS}}\left(1-\frac{T_{\mathrm{i}}-T_{\mathrm{R}}}{T_{\mathrm{m}}-T_{\mathrm{i}}}\right)}{\rho} F_{2} C_{\mathrm{p}}\left(T_{\mathrm{m}}-T_{\mathrm{i}}\right)}$

The experiments described in Ref 11 confirmed a pronounced increase in the particles velocity from about $750 \mathrm{~m} / \mathrm{s}$ for low-pressure WS to more than $960 \mathrm{~m} / \mathrm{s}$ for high-pressure WS at an optimal nitrogen flow rate of $1.0 \mathrm{~m}^{3} / \mathrm{min}$. The deposition velocity was shown to have a significant effect on adhesion strength of particles deposited by CS (Ref 31). Another important factor is increasing the particle temperature which reduces critical velocity required for cold spray deposits (Ref 27). Therefore, a simultaneous increase in particle velocity and temperature 

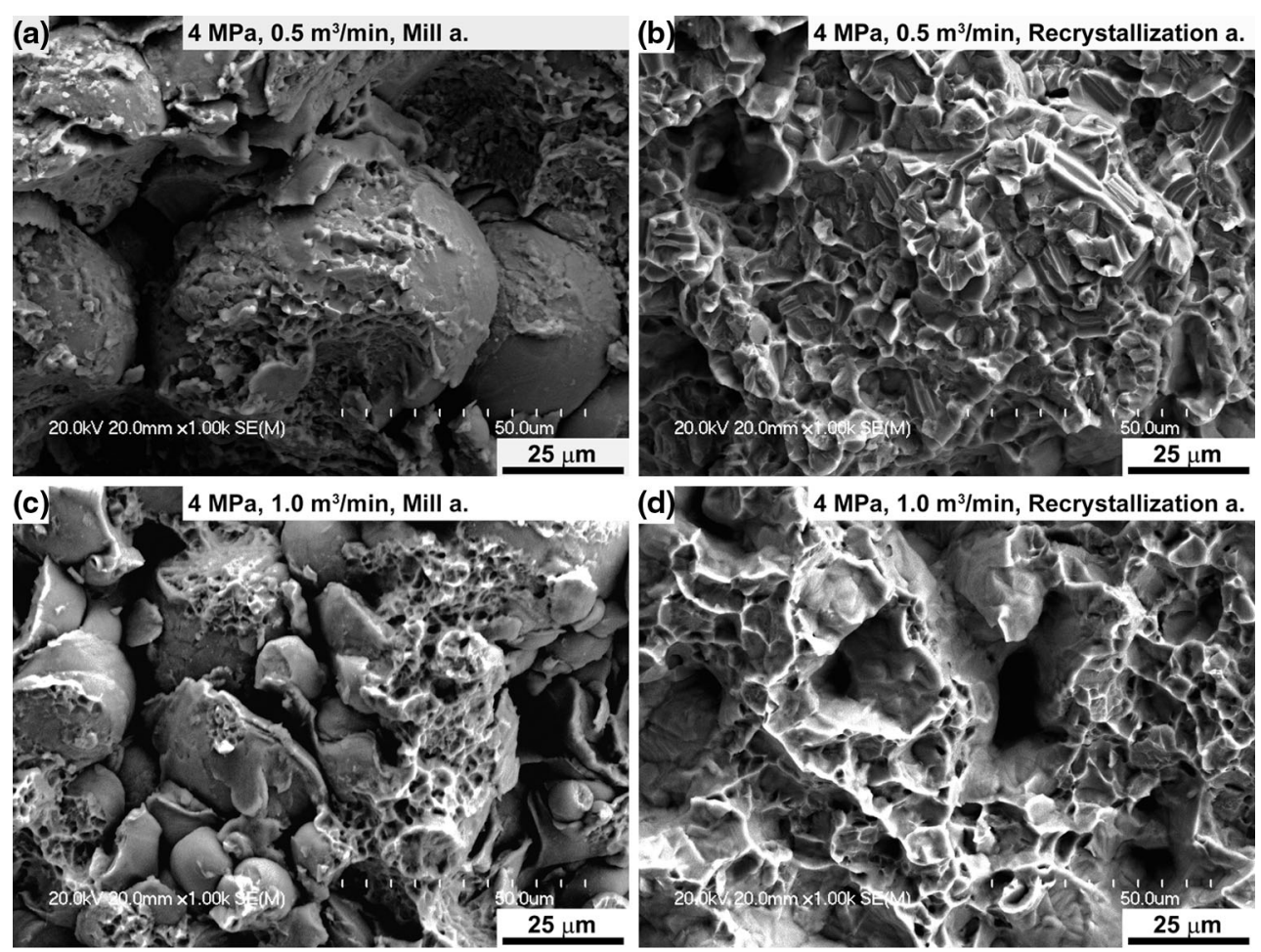

(d) $4=4 \mathrm{MPa}, 1.0 \mathrm{~m}^{3} / \mathrm{min}$, Recrystallization a.
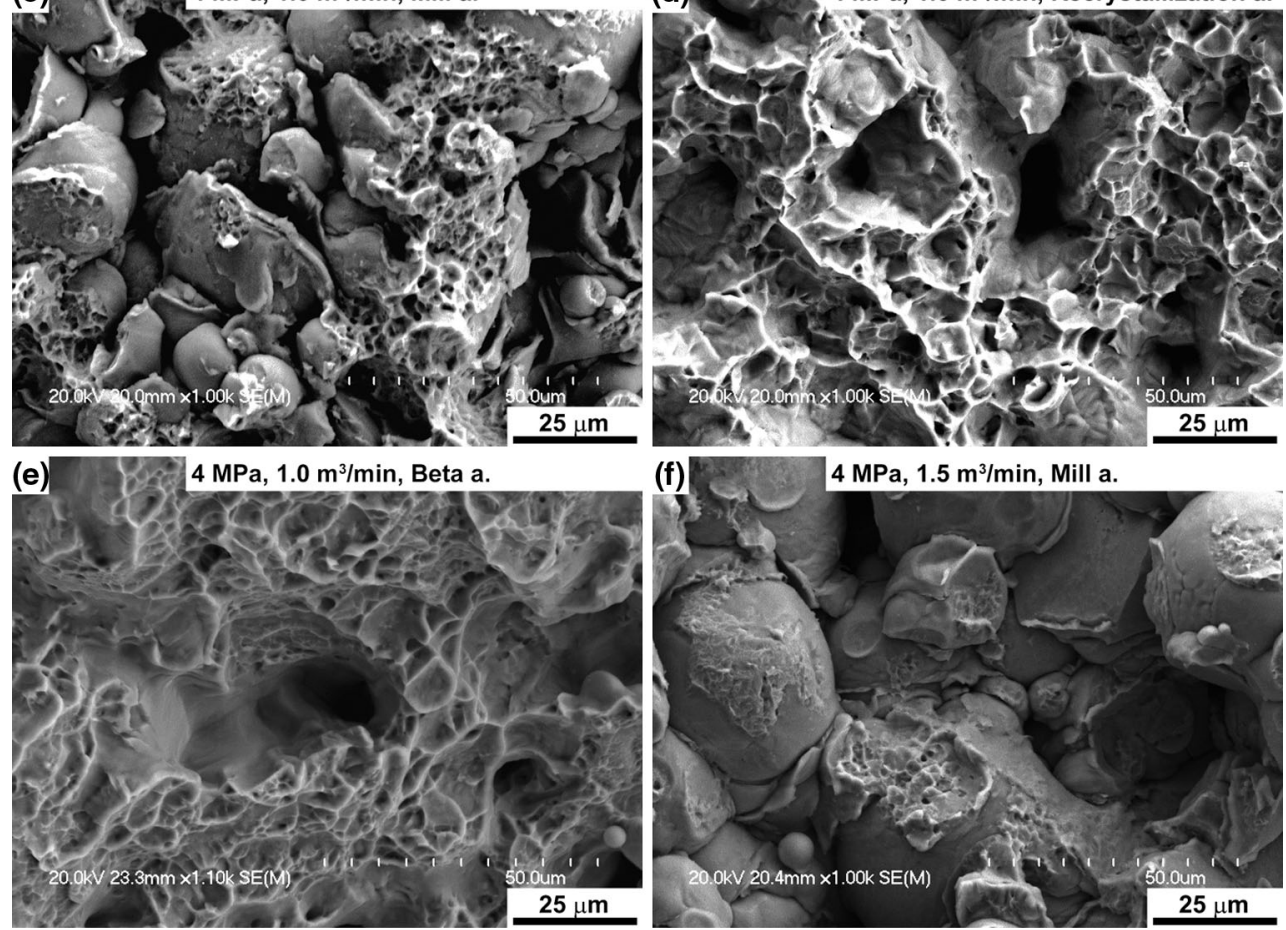

(g) $4 \mathrm{MPa}, 1.5 \mathrm{~m}^{3} / \mathrm{min}$, Recrystallization a.

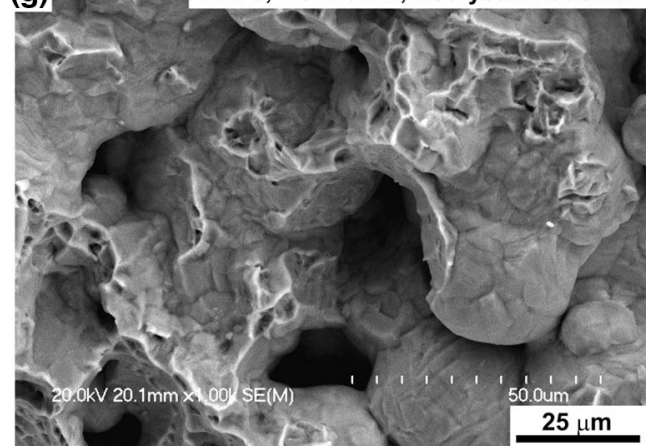

Fig. 13 Fracture surfaces of mini-specimens cut out of the heat-treated Ti-6Al-4V coating formed at three nitrogen flow rates of 0.5 (a, b), 1.0 (c, $\mathrm{d}, \mathrm{e})$ and $1.5 \mathrm{~m}^{3} / \mathrm{min}(\mathrm{f}, \mathrm{g})$

resulted in an improvement of the adhesion strength of single Ti-6Al-4V splats (Ref 31 ) as well as Ti-6Al-4V coatings by CS (Ref 3). Since, it is slightly drop of particle temperature by high-pressure WS when compared to lowpressure WS (Fig. 7), it is confirmed from Table 4 that the improvement of tensile strength was primary caused due to an increase in the particle velocity.

A comparison of the properties of Ti-6Al-4V coatings and the bulk material shows that the ultimate tensile strength of the coatings was significantly lower than the 
Fig. 14 Fracture surfaces and estimated plastic fracture areas of mini tensile specimens cut out of the as-sprayed (a) and heat-treated (b-mill; c-recrystallization and d-beta annealing) Ti-6Al-4V coating formed at $1.0 \mathrm{~m}^{3} / \mathrm{min}$ nitrogen flow rates

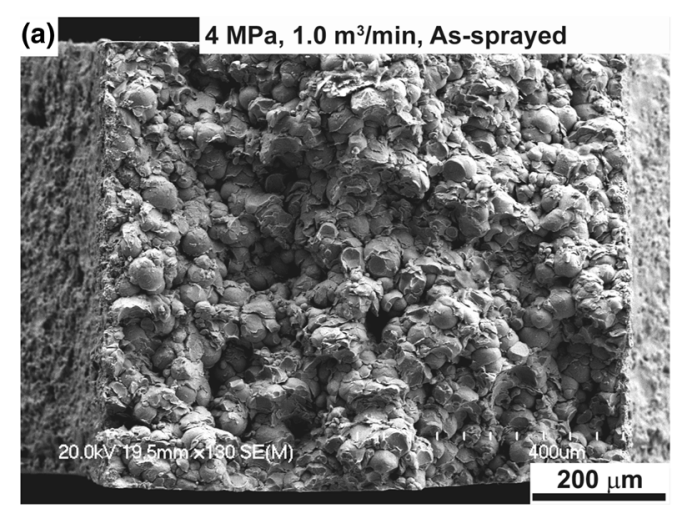

\author{
No plastic fracture
}

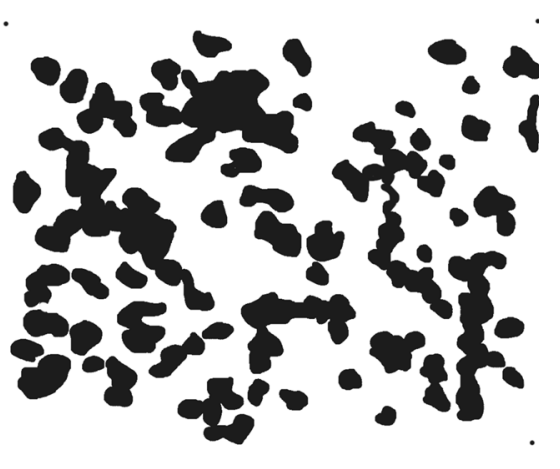

(c)
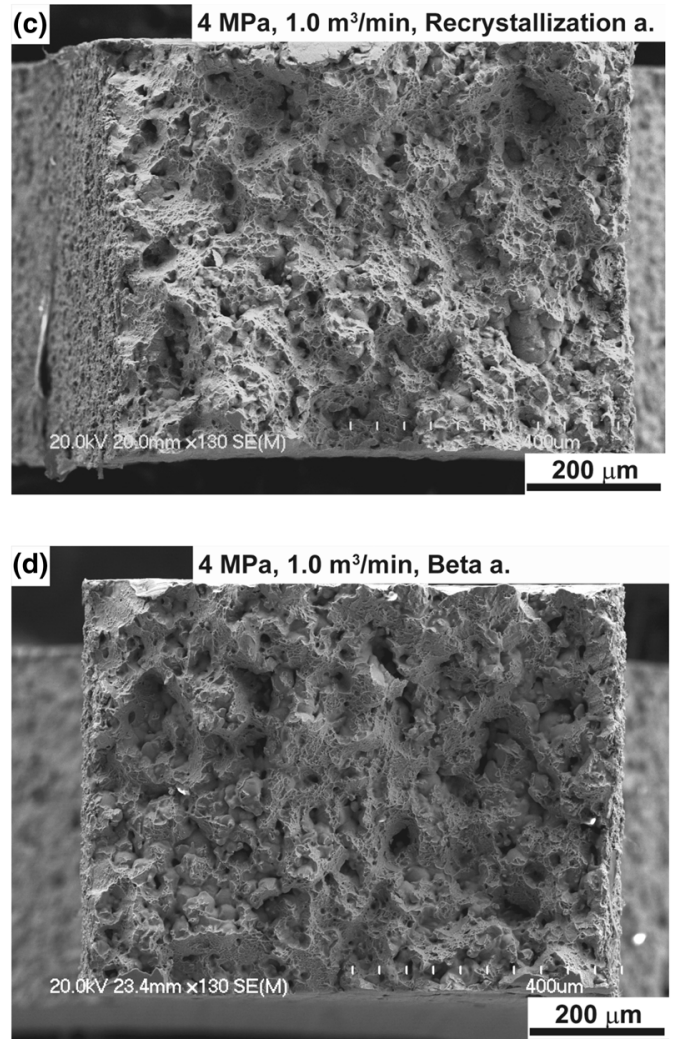
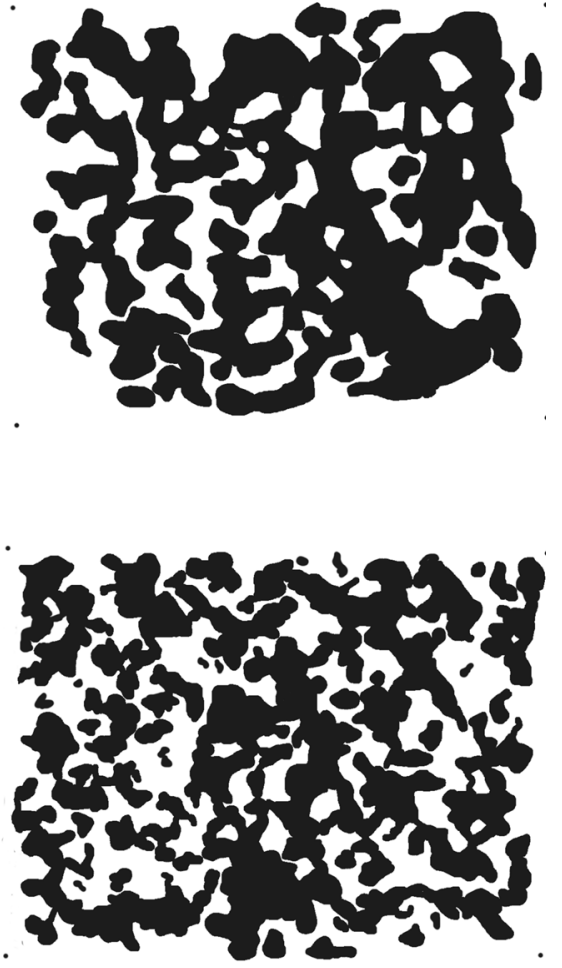
Table 4 Estimated plastic fracture areas of miniature tensile specimens by $1.0 \mathrm{~m}^{3} /$ min nitrogen flow rate

\begin{tabular}{lll}
\hline Nitrogen flow rate $\left(\mathrm{m}^{3} / \mathrm{min}\right)$ & \multicolumn{1}{c}{ Coating condition } & Ratio of plastically failed area (vol.\%) \\
\hline 1.0 & As-spray HP-WS & $\ldots$ \\
& Mill anealing & 31.1 \\
& Recrystallization anealing & 55.7 \\
& Beta anealing & 55.5 \\
\hline
\end{tabular}

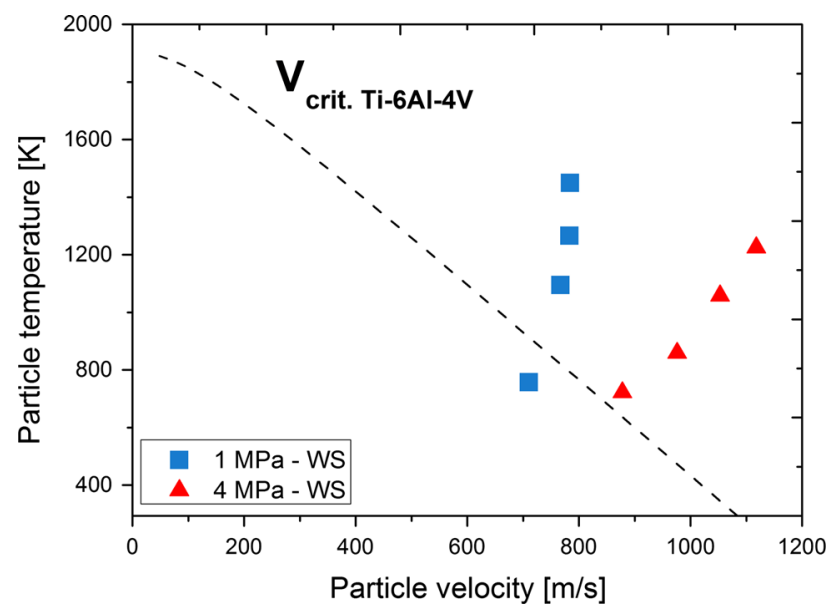

Fig. 15 Calculated particle velocity and temperature for low- and high-pressure Ti-6Al-4V coatings with critical velocity curve

values for the bulk material $\left(\sigma_{\text {UTSbulk }} \geq 828 \mathrm{MPa}\right)$ regardless of spraying conditions (Table 4). This effect was attributed to the existence of pores in the coatings, which reduces the effective cross-sectional area of the specimens and act as a stress concentrator. Porosity of the coatings was a reason for the decrease in the elastic modulus compared to the bulk material Ti-6Al-4V $\quad\left(E_{\text {bulk }} \geq\right.$ $105 \mathrm{GPa})$.

Interestingly, both series of coatings deposited by lowand high-pressure WS exhibited ductility below $1 \%$, which was significantly lower than the bulk materials ( $A_{\text {PLbulk }}$ $\geq 10 \%$ ). Although, our present spray conditions for highpressure WS satisfy the condition criteria for bonding, metallic bonding which provides plastic deformation was not observed on the fracture surfaces. There are possible several causes for the poor bond strength between deposited splats. Firstly, severe plastic deformation of particles could induce strain hardening during particle deposition. However, there is no clear evidence of strain hardening in microhardness measurements as shown in Fig. 5. Porosity volume and weak bonding between splats affect the indenter interaction with the coating and effectively reduce the value of microhardness. This effect was explained in detail in a previous work (Ref 11). Secondly, the high oxygen affinity of titanium and the high solid solubility of oxygen in titanium could form thick oxygen layers on particles during spraying and dissolve oxygen beneath them. It is often assumed that an oxide layer covering the surface of metallic particles is easily broken and removed by the adiabatic shear instability induced at particle-particle or particle-substrate interfaces during impacts of sprayed particles. However, Kim and Kuroda (Ref 32) reported that the surface oxide is not always completely removed by the impact of subsequent particle onto a previously deposited one and thus. A thin oxide can remain at the interfaces of titanium particles. Even with the presence of thin amorphous oxides at the interface of particles, bonding is still possible, but the mechanical properties of the coatings are affected by the morphology and thickness of the remained oxide (Ref 33). Another possible factor for poor plastic properties is the formation of nano- and micrograins in single particles resulting from the dynamic recrystallization of severely deformed grains during impact of titanium particles deposited by WS (Ref 34). The results of many works show that elongation to failure of nanometals determined from tensile test in general does not exceeds a few percent (Ref 35-37). The last possible factor is based on the argument that the discontinuity of the coating microstructure in the form of pores and unbounded interfaces acts as a structural stress concentration which can significant reduce the structural strength.

The results in this study suggest that the tensile strength of metallic coatings after heat treatment is a result of two competitive processes. The first one is healing-up of uncompleted interfaces by the formation of metallic bonding during a solid-state diffusion process during heat treatment which can significantly enhance structural strength. On the other hand, static recovery and recrystallization reduce the strain hardening result in a reduction in tensile strength. The forces of static recovery and recrystallization depend on the material, temperature, amount of deformation, texture, fraction of second phase, etc. The final outcome is complex and difficult to predict. The best set strength and ductility was found for the coating deposited by HP-WS at $1.0 \mathrm{~m}^{3} / \mathrm{min}$ (Fig. 12b). The optimal values of porosity and oxygen content were $1.9 \pm 1.6$ vol. $\%$ and 0.2 mass $\%$, respectively. Inferior mechanical properties for the other two samples resulted from the relatively high oxygen content $(0.59$ mass $\%)$ for the coating formed at 0.5 nitrogen flow rate (Fig. 12a), while the last coating formed at $1.5 \mathrm{~m}^{3} / \mathrm{min}$ nitrogen flow rate had a high porosity volume $(4.2 \pm 2.6$ vol. $\%)$ (Fig. 12c). 
Table 5 Parameters for critical velocity calculations

\begin{tabular}{llll}
\hline Nomenclature & & SI-units & Value \\
\hline$C_{\mathrm{p}}$ & Specific heat & $\mathrm{J} / \mathrm{kg} \mathrm{K}$ & 526 \\
$\sigma_{\mathrm{UTS}}$ & Tensile strength & $\mathrm{MPa}$ & 860 \\
$T_{\mathrm{m}}$ & Melting temperature & $\mathrm{K}$ & 1905 \\
$T_{\mathrm{R}}$ & Reference temperature $(293 \mathrm{~K})$ & $\mathrm{K}$ & 293 \\
$T_{\mathrm{i}}$ & Impact temperature & $\mathrm{K}$ & $\ldots$ \\
$\rho$ & Density & $\mathrm{kg} / \mathrm{m}^{3}$ & 4430 \\
$F_{1}, F_{2}$ & Empirical factors & $\ldots$ & $F_{1}=1.2, F_{2}=0.3$ \\
\hline
\end{tabular}

In addition, comparing mechanical properties of recrystallized and beta annealed coating formed at $1.0 \mathrm{~m}^{3} /$ min nitrogen flow rate, a significantly higher elongation to failure was noticed for the sample treated with beta annealing (3.04 $\pm 0.46 \%)$ compared to recrystallization annealing $(2.22 \pm 0.47 \%)$. At the same time, the tensile strength was almost unaffected $(820 \pm 15$ and $824 \pm 110 \mathrm{MPa}$, respectively). Because there are no significant differences in porosity $(1.6 \pm 1.1 \mathrm{vol} . \%$ after recrystallization annealing and $1.2 \pm 1.1 \mathrm{vol} . \%$ after beta annealing), the elongation change may be explained by differences in the microstructure of the coatings. It is well known that a fully lamellar microstructure is qualitative better in terms of elongation to failure compared to a fully equiaxed one (Ref 1). The most influential microstructure parameter on the mechanical properties of lamellar microstructures is the $\alpha$ colony size, which is controlled by the cooling rate from the $\beta$ heat treatment.

Figure 16 summarizes correlations between the ultimate tensile strength and total elongation to failure for the Ti$6 \mathrm{Al}-4 \mathrm{~V}$ coatings in the present study (LP- and HP-WS) as well as in the reference, cold spraying with nitrogen and helium as a propellant gas (CS-He) (Ref 3,13) and lowpressure plasma spraying (Ref 14). The values obtained for WS coatings formed at $1.0 \mathrm{~m}^{3} / \mathrm{min}$ nitrogen flow rate after various heat treatments were plotted in the graph. As a reference, the hatched area represents standard values of tensile strength and elongation to failure for bulk Ti-6Al4V (Ref 38).

In general, most of the as-sprayed coatings exhibit very low ductility $(<0.5 \%)$ regardless of the thermal spray process used. Only Vo et al. (Ref 13) obtained significant ductility (3.8\% elongation to failure) for CS-He-sprayed coatings, but the tensile strength was around one half (448 MPa) of the bulk material (828 MPa). Coatings deposited by LPPS (Ref 14) stand out with the highest tensile strength above $650 \mathrm{MPa}$ which is close to the bulk material, but the elongation to failure was less than $1 \%$. This high strength of the coatings by LPPS could be explained by the high process temperature, which resulted in low porosity (from 0.7 to 1.8 vol.\%) depending on the feedstock powder size. In addition, very good bonding was

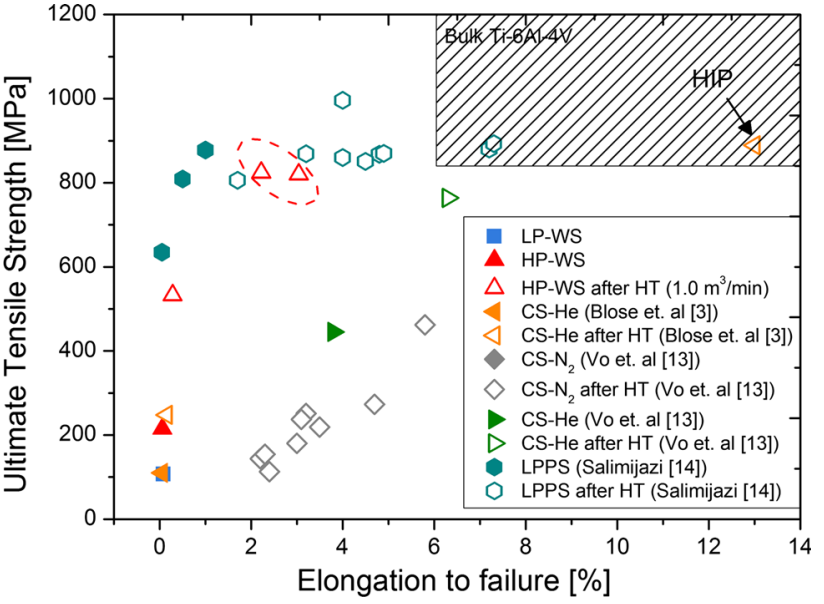

Fig. 16 Correlations between ultimate tensile strength and elongation to failure for Ti-6Al-4V coatings by low- and high-pressure warm spraying, cold spraying, low-pressure plasma spraying and bulk material

revealed in the cross section of LPPS coatings due to good interparticle wetting and possibly some sintering during spraying. The tensile strength of as-sprayed coatings by high-pressure WS ( $215 \pm 26 \mathrm{MPa})$ was between the values obtained for CS-He-sprayed coatings by Blose et al. (110 MPa) (Ref 3) and Vo et al. (448 MPa) (Ref 13).

In all the cases, the mechanical properties of all the Ti$6 \mathrm{Al}-4 \mathrm{~V}$ coatings were enhanced by heat treatment. With the exception for coatings produced by CS with nitrogen, the tensile strength of heat-treated coatings is nominally of about $800 \mathrm{MPa}$. Significant differences in ductility were found as a function of the thermal spray processes, the parameters and the thermal treatment. The highest elongation to failure $(13 \%)$ was obtained for CS-He coating treated by the hot isostatic pressing (HIP), which should have further reduced porosity (Ref 3 ). The Ti-6Al-4V deposits by HP-WS exhibited a lower level of elongation to failure as compared to CS-He-sprayed and HIPed coatings. Their values were in the range of ductility for coatings deposited by LPPS. Because of this, it may be stated that HP-WS when coupled with post-spray heat treatment can produce high-strength Ti-6Al-4V coatings with reasonable plasticity without the need for vacuum chamber (LPPS) or 
helium as a propellant gas (CS-He). This offers a possibility of forming Ti6-Al-4V deposits with clear economic benefits when compared to spray processes requiring heavy installation or running cost.

\section{Conclusions}

The microstructure and mechanical properties of assprayed and heat-treated 3-mm-thick Ti-6Al-4V coatings produced by low- and high-pressure WS were investigated. Coating microstructure, porosity, oxygen content, microhardness and tensile properties were characterized.

1. The nitrogen flow rate, which is one of the main parameters of WS affecting mainly particle temperature, has a remarkable influence on the determined mechanical properties of the Ti-6Al-4V coatings. The best mechanical properties (ultimate tensile strength and elongation to failure) were found for the coating by $1.0 \mathrm{~m}^{3} / \mathrm{min}$ nitrogen flow rate.

2. Due to particle velocity enhancement in high-pressure WS, Ti-6Al-4V coatings with better quality in terms of both density and purity (porosity and oxygen content) in comparison with low-pressure WS were formed.

3. Lower values of both the porosity and oxygen content result in higher values for ultimate strength and Young's modulus, but these factor did not appear to be the main factor in determining elongation to failure.

4. After recrystallization and beta annealing, WS coatings showed a significant increase in the amount of metallic bonds among the deposited particles, which resulted in an improvement of Young's modulus, ultimate tensile strength and elongation to failure. The best mechanical properties were found for the coating by $1.0 \mathrm{~m}^{3} / \mathrm{min}$ nitrogen flow rate.

5. The mechanical properties of WS coatings were comparable to these ones obtained for Ti-6Al-4V coatings produced by LPPS and CS. It was found that Ti-6Al-4V coatings strength at the level similar to bulk material and elongation up to $4 \%$ can be recovered by post-spray heat treatment.

Open Access This article is distributed under the terms of the Creative Commons Attribution 4.0 International License (http://creative commons.org/licenses/by/4.0/), which permits unrestricted use, distribution, and reproduction in any medium, provided you give appropriate credit to the original author(s) and the source, provide a link to the Creative Commons license, and indicate if changes were made.

\section{References}

1. G. Lutjering and J.C. Williams, Titanium, 2nd ed., Springer, Berlin, 2003, 2007
2. R.H. Morgan, C.J. Sutcliffe, J. Pattison, M. Murphy, C. Gallagher, A. Papworth, P. Fox, and W. O'Neill, Cold Gas Dynamic Manufacturing-A New Approach to Near-Net Shape Metal Component Fabrication, Mater. Res. Soc. Symp. Proc., 2003, 758, p 73-84

3. R.E. Blose, B.H. Walker, R.M. Walker, and S.H. Froes, New Opportunities to Use Cold Spray Process for Applying Additive Features to Titanium Alloys, Met. Powder Rep., 2006, 61, p 3037

4. J.C. Lee, H.J. Kang, W.S. Chu, and S.H. Ahn, Repair of Damaged Mold Surface by Cold-Spray Method, Ann. CIRP, 2007, 56, p 577-580

5. V.K. Champagne, The Repair of Magnesium Rotorcraft Components by Cold Spray, J. Fail. Anal. Prev., 2008, 8, p 164-175

6. R. Huang and H. Fukanuma, Study of the Influence of Particle Velocity on Adhesive Strength of Cold Spray Deposits, J. Therm. Spray Technol., 2012, 21(3-4), p 541-549

7. D.L. Gilmore, R.C. Dykhuizen, R.A. Neiser, T.J. Roemer, and M.F. Smith, Particle Velocity and Deposition Efficiency in the Cold Spray Process, J. Therm. Spray Technol., 1999, 8(4), p 576582

8. S. Kuroda, J. Kawakita, M. Watanabe, and H. Katanoda, Warm Spraying-A Novel Coating Process Based on High-Velocity Impact of Solid Particles, Sci. Technol. Adv. Mater., 2008, 9(3), p $1-17$

9. J. Kawakita, H. Katanoda, M. Watanabe, K. Yokoyama, and S. Kuroda, Warm Spraying: An Improved Spray Process to Deposit Novel Coatings, Surf. Coat. Technol., 2008, 202(18), p 43694373

10. S. Kuroda, M. Watanabe, K.-H. Kim, and H. Katanoda, Current Status and Future Prospects of Warm Spray Technology, $J$. Therm. Spray Technol., 2011, 20(4), p 653-676

11. R.M. Molak, H. Araki, M. Watanabe, H. Katanoda, N. Ohno, and S. Kuroda, Warm Spray Forming of Ti-6Al-4V, J. Therm. Spray Technol., 2014, 23(1-2), p 197-212

12. W. Wong, E. Irissou, J.G. Legoux, P. Vo, and S. Yue, Powder Processing and Coating Heat Treatment on Cold Sprayed Ti-6Al4V Alloy, Mater. Sci. Forum, 2012, 706-709, p 258-263

13. P. Vo, E. Irissou, J.-G. Legoux, and S. Yue, Mechanical and Microstructural Characterization of Cold-Sprayed Ti-6Al-4V After Heat Treatment, J. Therm. Spray Technol., 2013, 22(6), p 954-964

14. H.R. Salimijazi, T.W. Coyle, and J. Mostaghimi, Vacuum Plasma Spraying: A New Concept for Manufacturing Ti-6Al-4V Structures, JOM-US, Sept. 2006, pp 50-56

15. H. Katanoda, B. Sun, N. Ohno, H. Fukanuma, S. Kuroda, M. Watanabe, and O. Ohashi, Design and Development of HighPressure Warm Spray Gun, Proceedings of International Thermal Spray Conference 2013, Busan, Republic of Korea, May 13-15, 2013

16. R. Molak, R.M. Molak, H. Araki, M. Watanabe, H. Katanoda, N. Ohno, and S. Kuroda, Effects of Spray Parameters and Heat Treatment on the Microstructure and Mechanical Properties of Titanium Coatings Formed by Warm Spraying, J. Therm. Spray Technol., 2016, 24(8), p 1459-1479

17. R.M. Molak, M.E. Kartal, Z. Pakiela, and K.J. Kurzydlowski, The Effect of Specimen Size and Surface Conditions on the Local Mechanical Properties of 14MoV6 Ferritic-Pearlitic Steel, Mater. Sci. Eng. A Struct., 2016, 651, p 810-821

18. Joint Committee for Guides in Metrology 100:2008, Evaluation of Measurement Data-Guide to the Expression of Uncertainty in Measurement, JCGM 2008

19. ASM Handbook, Metals Handbook, Vol. 4 Heat Treating, 9th ed., ASM International, Materials Park, OH, USA, 1981

20. J.-S. Yu, H.-J. Kim, I.-H. Oh, and K.-A. Lee, Densification and Purification of Cold Sprayed Ti Coating Layer by Using 
Annealing in Different Heat Treatment Environments, $A d v$. Mater. Res., 2013, 602-604, p 1604-1608

21. W. Wong, E. Irissou, P. Vo, M. Sone, F. Bernier, J.-G. Legoux, H. Fukanuma, and S. Yue, Cold Spray Forming of Inconel 718, J. Therm. Spray Technol., 2013, 22(2), p 413-421

22. S.H. Zahiri, D. Fraser, and M. Jahedi, Recrystallization of Cold Spray-Fabricated CP Titanium Structures, J. Therm. Spray Technol., 2009, 18(1), p 16-22

23. T. Stoltenhoff, C. Borchers, F. Gartner, and H. Kreye, Microstructures and Key Properties of Cold-Sprayed and Thermally Sprayed Copper Coatings, Surf. Coat. Technol., 2006, 200, p 4947-4960

24. M. Yua, W.-Y. Li, Ch Zhang, and H. Liao, Effect of Vacuum Heat Treatment on Tensile Strength and Fracture Performance of Cold-Sprayed Cu-4Cr-2Nb Coatings, Appl. Surf. Sci., 2011, 257, p 5972-5976

25. X.-M. Meng, J.-B. Zhang, W. Han, J. Zhao, and Y.-L. Liang, Influence of Annealing Treatment on the Microstructure and Mechanical Performance of Cold Sprayed 304 Stainless Steel Coating, Appl. Surf. Sci., 2011, 258, p 700-704

26. A.C. Hall, D.J. Cook, R.A. Neiser, T.J. Roemer, and D.A. Hirschfeld, The Effect of a Simple Annealing Heat Treatment on the Mechanical Properties of Cold-Sprayed Aluminum, J. Therm. Spray Technol., 2006, 15(2), p 233-238

27. T. Schmidt, F. Gärtner, H. Assadi, and H. Kreye, Development of a Generalized Parameter Window for Cold Spray Deposition, Acta Mater., 2006, 54, p 729-742

28. T. Schmidt, F. Gärtner, and H. Kreye, New Developments in Cold Spray Based on Higher Gas and Particle Temperatures, $J$. Therm. Spray Technol., 2006, 15(4), p 488-494

29. G. Bae, Y. Xiong, S. Kumar, K. Kang, and Ch. Lee, General Aspects of Interface Bonding in Kinetic Sprayed Coatings, Acta Mater., 2008, 56, p 4858-4868
30. M. Grujicic, C.L. Zhao, W.S. DeRosset, and D. Helfritch, Adiabatic Shear Instability Based Mechanism for Particles/Substrate Bonding in the Cold-Gas Dynamic-Spray Process, Mater. Design, 2004, 25, p 681-688

31. D. Goldbaum, J.M. Shockley, R.R. Chromik, A. Rezaeian, S. Yue, J.-G. Legoux, and E. Irissou, The Effect of Deposition Conditions on Adhesion Strength of Ti and Ti6Al4V Cold Spray Splats, J. Therm. Spray Technol., 2012, 21(2), p 2012-2289

32. K.H. Kim and S. Kuroda, Amorphous Oxide Film Formed by Dynamic Oxidation During Kinetic Spraying of Titanium at High Temperature and Its Role in Subsequent Coating Formation, Scr. Mater., 2010, 63, p 215-218

33. K.H. Kim, M. Watanabe, K. Mitsuishi, J. Kawakita, T. Wu, and S. Kuroda, Microstructure Observation on the Interface Between Warm Spray Deposited Titanium Powder and Steel Substrate, Thermal Spray 2008: Proceedings of the International Thermal Spray Conference, 2008, pp 1277-1282

34. K.H. Kim, M. Watanabe, J. Kawakita, and S. Kuroda, Grain Refinement in a Single Titanium Powder Particle Impacted at High Velocity, Scr. Mater., 2008, 59, p 768-771

35. M. Legros, B.R. Elliott, M.N. Rittner, J.R. Weertman, and K.J. Hemker, Microsample Tensile Testing of Nanocrystalline Metals, Philos. Mag. A, 2000, 80(4), p 1017-1025

36. R.Z. Valieva, I.V. Alexandrova, Y.T. Zhua, and T.C. Lowea, Paradox of Strength and Ductility in Metals Processed by Severe Plastic Deformation, J. Mater. Res., 2002, 17(1), p 5-8

37. C.C. Koch, Optimization of Strength and Ductility in Nanocrystalline and Ultrafine Grained Metals, Scr. Mater., 2003, 49(7), p 657-662

38. ASTM Standard B265-03, Standard Specification for Titanium and Titanium Alloy Strip, Sheet, and Plate, ASTM International, West Conshohocken, PA, USA, 2003 